\title{
International Geomagnetic Reference Field: the thirteenth generation
}

\author{
P. Alken ${ }^{1,2^{*}}$ (D) E. Thébault ${ }^{3}$, C. D. Beggan ${ }^{4}$, H. Amit ${ }^{3}$, J. Aubert ${ }^{6}$, J. Baerenzung ${ }^{22}$, T. N. Bondar ${ }^{17}$, W. J. Brown ${ }^{4}$, \\ S. Califf ${ }^{1,2}$, A. Chambodut ${ }^{12}$, A. Chulliat ${ }^{1,2}$, G. A. Cox, , C. C. Finlay ${ }^{5}$, A. Fournier ${ }^{6}$, N. Gillet ${ }^{7}$, A. Grayver ${ }^{28}$, \\ M. D. Hammer ${ }^{5}$, M. Holschneider22, L. Huder ${ }^{7}$, G. Hulot ${ }^{6}$, T. Jager ${ }^{16}$, C. Kloss ${ }^{5}$, M. Korte ${ }^{10}$, W. Kuang ${ }^{23}$, \\ A. Kuvshinov ${ }^{28}$, B. Langlais ${ }^{3}$, J.-M. Léger ${ }^{16}$, V. Lesur ${ }^{6}$, P. W. Livermore ${ }^{8}$, F. J. Lowes ${ }^{9}$, S. Macmillan ${ }^{4}$, W. Magnes ${ }^{15}$, \\ M. Mandea ${ }^{27}$, S. Marsal ${ }^{26}$, J. Matzka ${ }^{10}$, M. C. Metman ${ }^{8}$, T. Minami ${ }^{18,20}$, A. Morschhauser $^{10}$, J. E. Mound ${ }^{8}$, M. Nair ${ }^{1,2}$, \\ S. Nakano ${ }^{19}$, N. Olsen ${ }^{5}$, F. J. Pavón-Carrasco ${ }^{24,25}$, V. G. Petrov ${ }^{17}$, G. Ropp ${ }^{6}$, M. Rother ${ }^{10}$, T. J. Sabaka ${ }^{23}$, S. Sanchez ${ }^{21}$, \\ D. Saturnino ${ }^{3}$, N. R. Schnepf ${ }^{1,2}$, X. Shen ${ }^{13}$, C. Stolle ${ }^{10}$, A. Tangborn ${ }^{23}$, L. Tøffner-Clausen ${ }^{5}$, H. Toh ${ }^{11}$, J. M. Torta ${ }^{26}$, \\ J. Varner ${ }^{1,2}$, F. Vervelidou ${ }^{10}$, P. Vigneron ${ }^{6}$, I. Wardinski ${ }^{12}$, J. Wicht ${ }^{21}$, A. Woods ${ }^{1,2}$, Y. Yang ${ }^{13}$, Z. Zeren ${ }^{13}$ and B. Zhou ${ }^{14}$
}

\begin{abstract}
In December 2019, the International Association of Geomagnetism and Aeronomy (IAGA) Division V Working Group ( $V$-MOD) adopted the thirteenth generation of the International Geomagnetic Reference Field (IGRF). This IGRF updates the previous generation with a definitive main field model for epoch 2015.0, a main field model for epoch 2020.0, and a predictive linear secular variation for 2020.0 to 2025.0. This letter provides the equations defining the IGRF, the spherical harmonic coefficients for this thirteenth generation model, maps of magnetic declination, inclination and total field intensity for the epoch 2020.0, and maps of their predicted rate of change for the 2020.0 to 2025.0 time period.
\end{abstract}

Keywords: IGRF, Magnetic field modeling, Geomagnetism

\section{Introduction}

The International Geomagnetic Reference Field (IGRF) is a set of spherical harmonic coefficients which can be input into a mathematical model in order to describe the large-scale, time-varying portion of Earth's internal magnetic field between epochs 1900 A.D. and the present. The IGRF is produced and maintained by an international task force of scientists under the auspices of the International Association of Geomagnetism and Aeronomy (IAGA) Working Group V-MOD. This thirteenth generation IGRF has been derived from observations recorded by satellites, ground observatories, and magnetic surveys (see Appendix 1 for a list of World Data System data centers and services). IGRF is routinely used

\footnotetext{
*Correspondence: alken@colorado.edu

${ }^{2}$ NOAA National Centers for Environmental Information, Boulder, CO, USA Full list of author information is available at the end of the article
}

by the scientific community to study Earth's core field, space weather, electromagnetic induction, and local magnetic anomalies in the lithosphere. It is also widely used in satellite attitude determination and control systems and other applications requiring orientation information.

Earth's core field changes continuously and unpredictably on timescales ranging from months to millions of years. In order to account for temporal changes on timescales of a few years, the IGRF is regularly revised, typically every 5 years. Table 1 summarizes the current and past generations of IGRF. Each generation is composed of a set of model coefficients representing the internal time-varying geomagnetic field, which are provided in 5 -year intervals. The years for which coefficients are provided are called model epochs. The coefficients of a certain epoch represent a snapshot of the geomagnetic field at that time, and can be labeled either as a Definitive Geomagnetic Reference Model (DGRF) or as an IGRF. 
Table 1 Summary of IGRF generations, validity periods, release years, and references

\begin{tabular}{llllll}
\hline Full name & Short name & Validity period & Definitive period & Release year & Reference \\
\hline IGRF 13th generation & IGRF-13 & 1900.0 to 2025.0 & 1945.0 to 2015.0 & 2019 & This article \\
IGRF 12th generation & IGRF-12 & 1900.0 to 2020.0 & 1945.0 to 2010.0 & 2014 & Thébault et al. (2015) \\
IGRF 11th generation & IGRF-11 & 1900.0 to 2015.0 & 1945.0 to 2005.0 & 2009 & Finlay et al. (2010a) \\
IGRF 10th generation & IGRF-10 & 1900.0 to 2010.0 & 1945.0 to 2000.0 & 2004 & Maus et al. (2005); Macmillan and Maus (2005) \\
IGRF 9th generation & IGRF-9 & 1900.0 to 2005.0 & 1945.0 to 2000.0 & 2003 & Macmillan et al. (2003) \\
IGRF 8th generation & IGRF-8 & 1900.0 to 2005.0 & 1945.0 to 1990.0 & 1999 & Mandea and Macmillan (2000) \\
IGRF 7th generation & IGRF-7 & 1900.0 to 2000.0 & 1945.0 to 1990.0 & 1995 & Barton (1997) \\
IGRF 6th generation & IGRF-6 & 1945.0 to 1995.0 & 1945.0 to 1985.0 & 1991 & Langel (1992) \\
IGRF 5th generation & IGRF-5 & 1945.0 to 1990.0 & 1945.0 to 1980.0 & 1987 & Barraclough et al. (1987); Langel et al. (1988) \\
IGRF 4th generation & IGRF-4 & 1945.0 to 1990.0 & 1965.0 to 1980.0 & 1985 & Barraclough (1987) \\
IGRF 3rd generation & IGRF-3 & 1965.0 to 1985.0 & 1965.0 to 1975.0 & 1981 & Peddie (1982) \\
IGRF 2nd generation & IGRF-2 & 1955.0 to 1980.0 & - & 1975 & IAGA Division I Study Group (1975) \\
IGRF 1st generation & IGRF-1 & 1955.0 to 1975.0 & - & Cain and Cain (1971); Zmuda (1971a, 1971b) \\
\hline
\end{tabular}

DGRF models are so labeled because they have been built from the best available data sources of that time period and therefore are unlikely to be improved in future IGRF revisions. Models labeled as IGRF are non-definitive, and will likely be revised in the future as more data are collected. DGRF models have been built only starting in 1945. Details of the history of IGRF can be found in Barton (1997) and Macmillan and Finlay (2011). Past generations of IGRF models are archived at https://www.ngdc. noaa.gov/IAGA/vmod/igrf_old_models.html. Since later IGRFs can revise model parameters for past epochs, it is important to record which generation of IGRF was used to process a particular dataset, so that the original data can be recovered and reprocessed with the latest generation of IGRF if needed.

In this paper, we focus on the thirteenth generation of IGRF, known hereafter as IGRF-13. IGRF-13 provides a DGRF model for epoch 2015.0, an IGRF model for epoch 2020.0, and a predictive IGRF secular variation model for the 5-year time interval 2020.0 to 2025.0. For epochs 1900.0 to 2010.0, the IGRF-13 model coefficients are unchanged from IGRF-12. IGRF-13 was finalized in December 2019 by a task force of IAGA Working Group V-MOD. In the following sections, we will describe the IGRF model, provide the final set of IGRF-13 coefficients, and briefly discuss large-scale features of the geomagnetic field at Earth's surface as revealed by the updated model.

\section{Mathematical formulation of the IGRF model}

The IGRF describes the main geomagnetic field $\mathbf{B}(r, \theta, \phi, t)$ which is produced by internal sources primarily inside Earth's core. The IGRF is valid on and above Earth's surface, where the main geomagnetic field can be described as the gradient of a scalar potential, $\mathbf{B}=-\nabla V$, and the potential function $V(r, \theta, \phi, t)$ is represented as a finite series expansion in terms of spherical harmonic coefficients, $g_{n}^{m}, h_{n}^{m}$, also known as the Gauss coefficients:

$$
\begin{array}{r}
V(r, \theta, \phi, t)=a \sum_{n=1}^{N} \sum_{m=0}^{n}\left(\frac{a}{r}\right)^{n+1} . \\
{\left[g_{n}{ }^{m}(t) \cos m \phi+h_{n}{ }^{m}(t) \sin m \phi\right] P_{n}^{m}(\cos \theta)}
\end{array}
$$

Here, $r, \theta, \phi$ refer to coordinates in a geocentric spherical coordinate system, with $r$ being radial distance from the center of the Earth, and $\theta, \phi$ representing geocentric co-latitude and longitude, respectively. A reference radius $a=6371.2 \mathrm{~km}$ is chosen to approximate the mean Earth radius. The $P_{n}^{m}(\cos \theta)$ are Schmidt semi-normalized associated Legendre functions of degree $n$ and order $m$ (Winch et al. 2005). The parameter $N$ specifies the maximum spherical harmonic degree of expansion, and was chosen to be 10 up to and including epoch 1995, after which it increases to 13 to account for the smaller scale internal signals which can be captured by high-resolution satellite missions such as Ørsted, CHAMP and Swarm. The Gauss coefficients $g_{n}^{m}(t), h_{n}^{m}(t)$ change in time and are provided in units of nanoTesla (nT) in IGRF-13 at 5 -year epoch intervals. The time dependence of these parameters is modeled as piecewise linear, and is given by

$$
\begin{aligned}
& g_{n}^{m}(t)=g_{n}^{m}\left(T_{t}\right)+\left(t-T_{t}\right) \dot{g}_{n}^{m}\left(T_{t}\right), \\
& h_{n}^{m}(t)=h_{n}^{m}\left(T_{t}\right)+\left(t-T_{t}\right) \dot{h}_{n}^{m}\left(T_{t}\right),
\end{aligned}
$$

where $g_{n}^{m}\left(T_{t}\right), h_{n}^{m}\left(T_{t}\right)$ are the Gauss coefficients at epoch $T_{t}$, which immediately precedes time $t$. The model epochs in IGRF-13 are provided in exact multiples of 5 years starting in 1900 and ending in 2020 (see Table 2), so that $T_{t} \leq t<T_{t}+5$. For $T_{t}<2020$, the parameters 


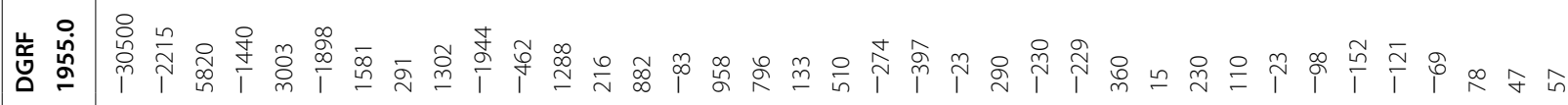

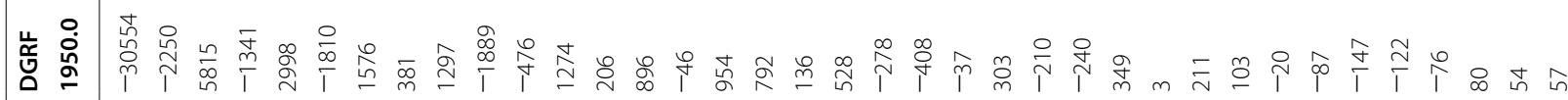

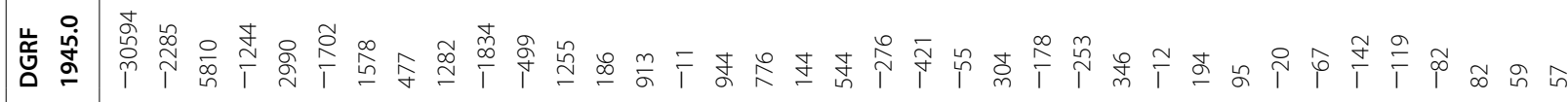

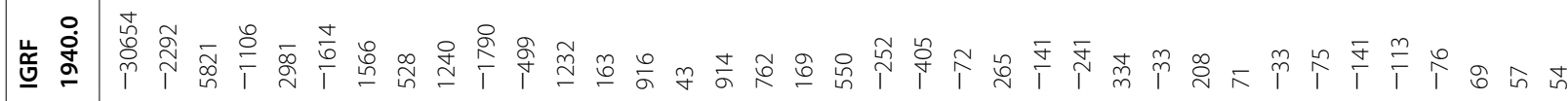

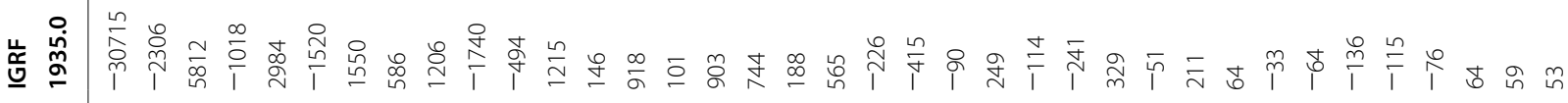

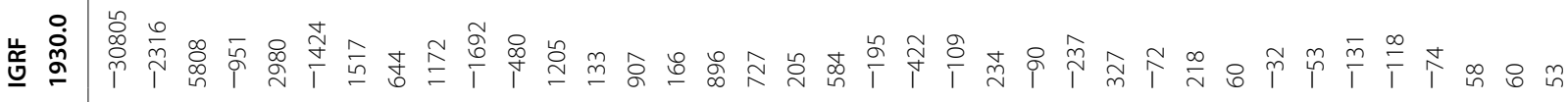

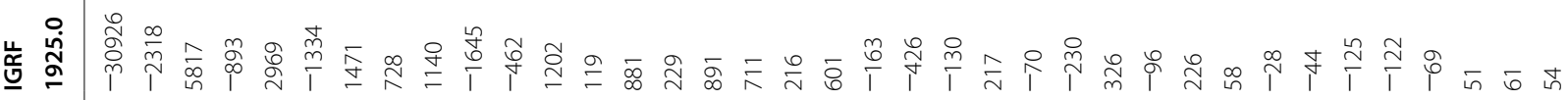

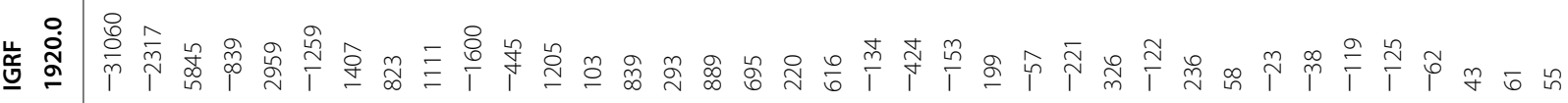

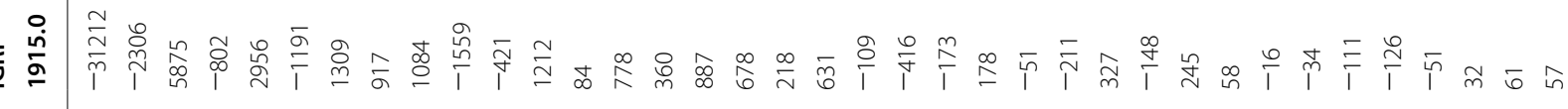

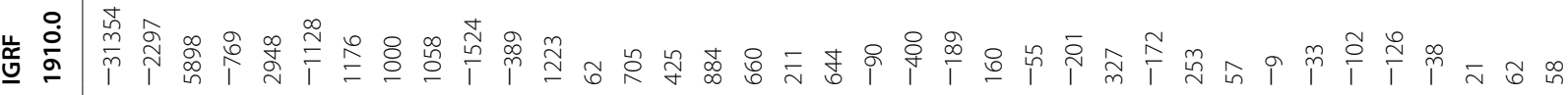

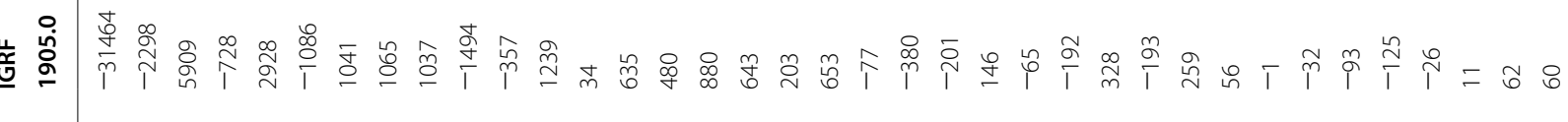

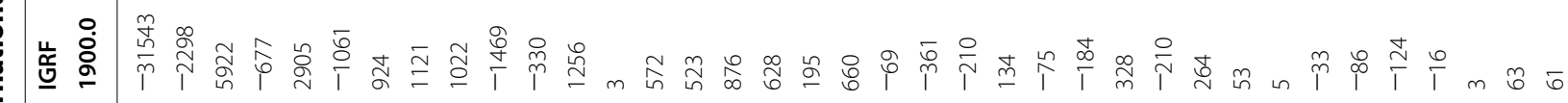
Ḋँ (1)

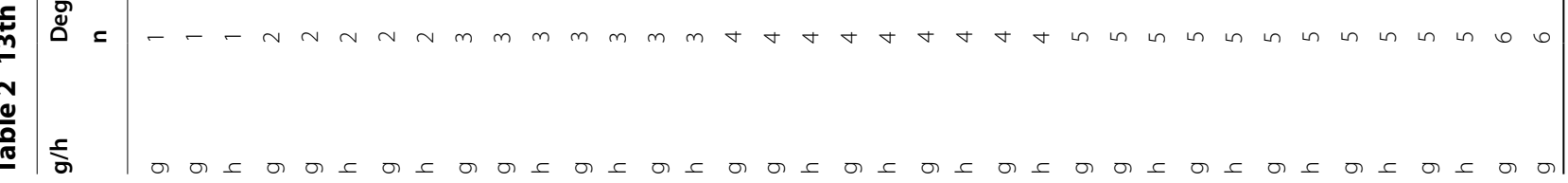


嵌 离

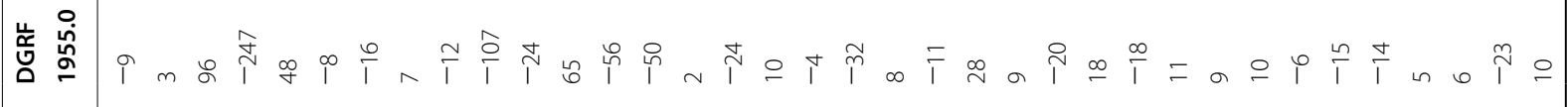

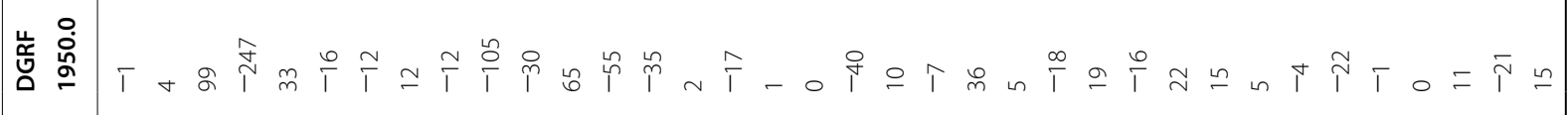
岕旁 岕 竎

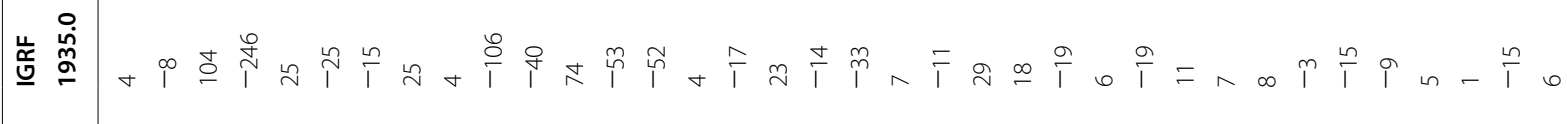
岕 㒸

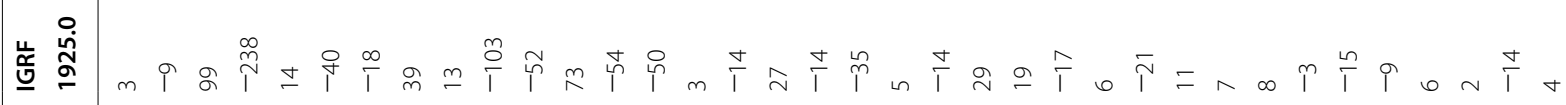
岕 京

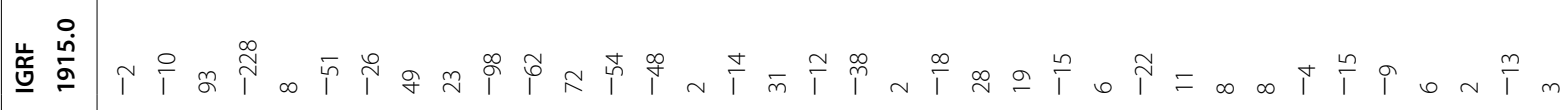
岕兽 离 岕悹 岕 离

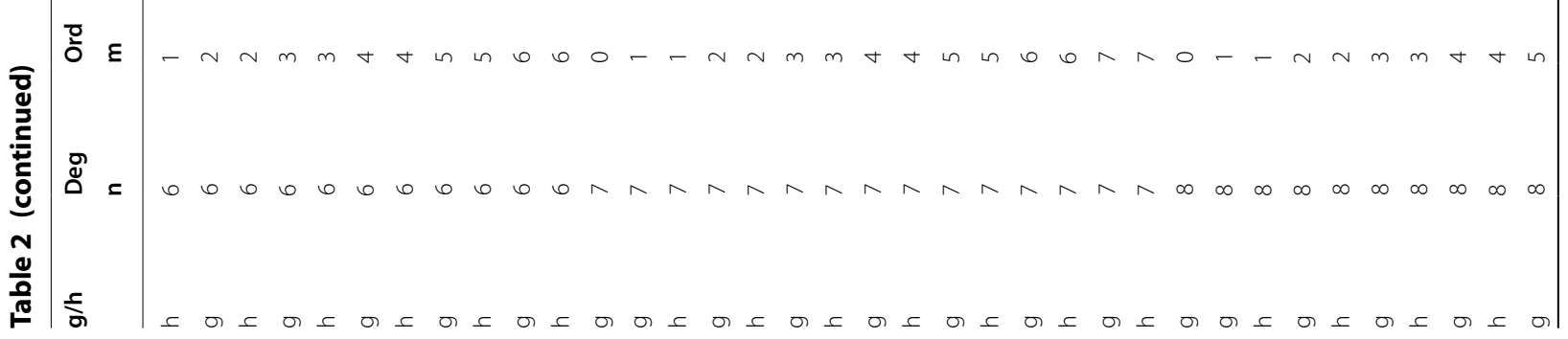




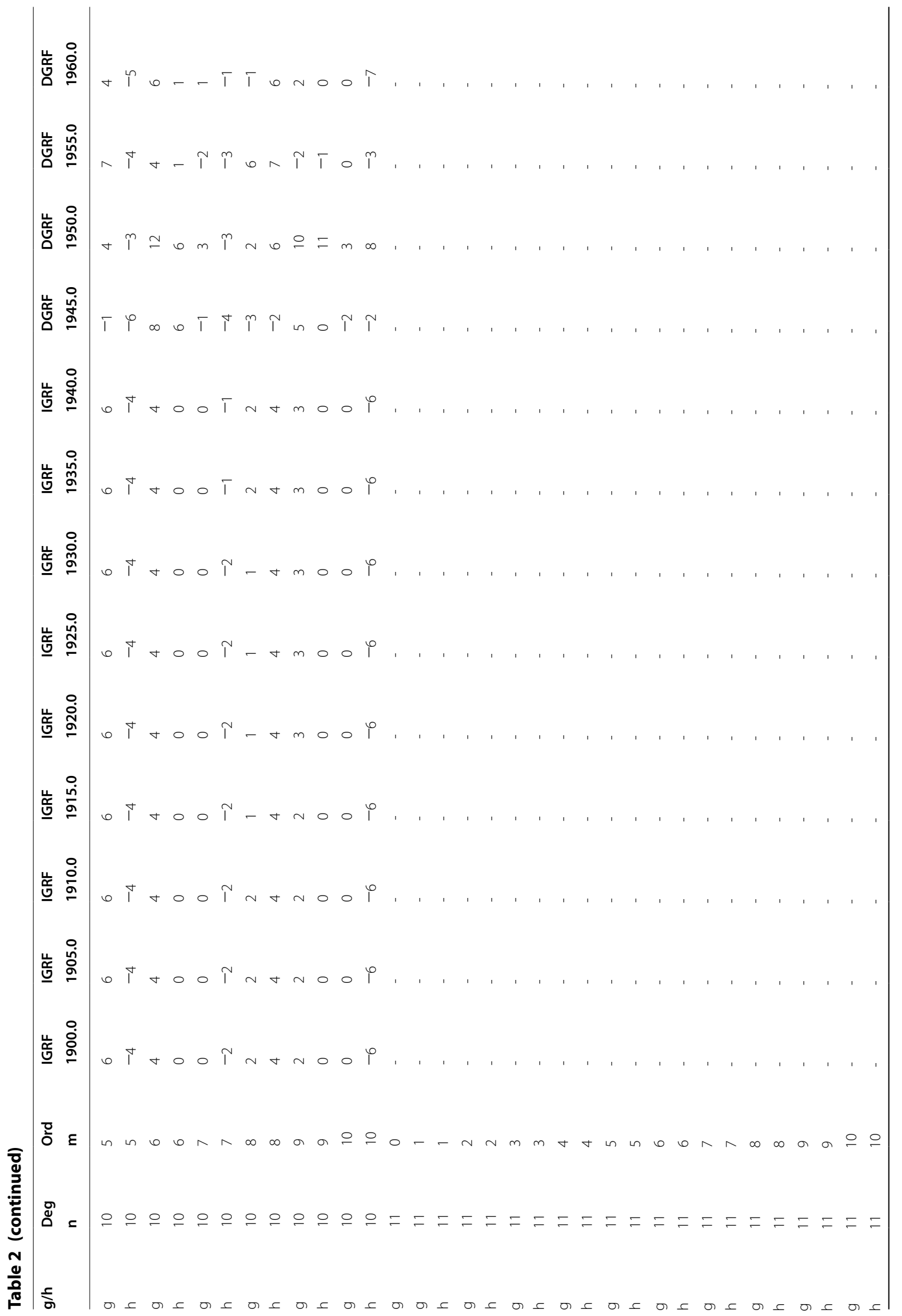




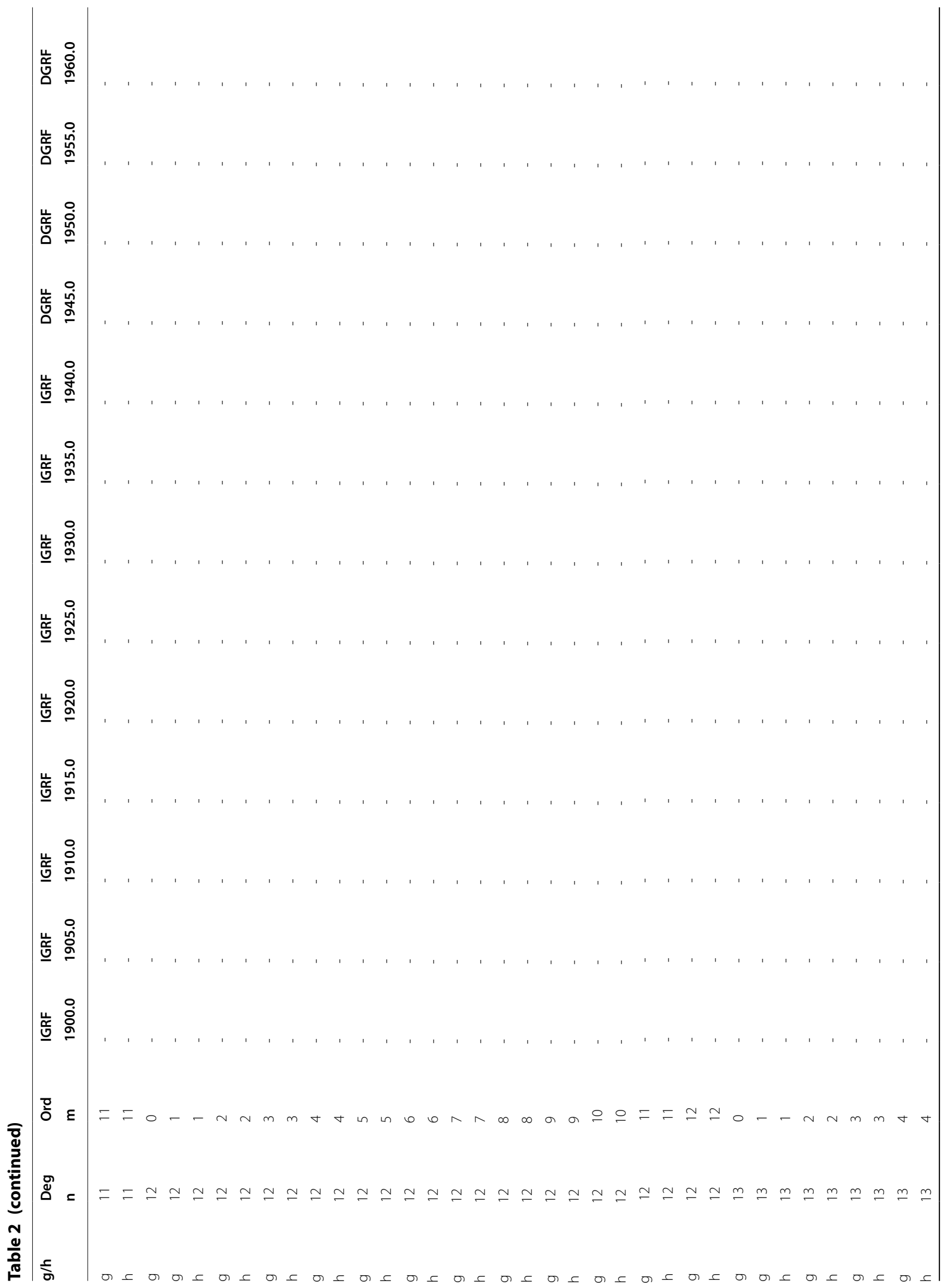




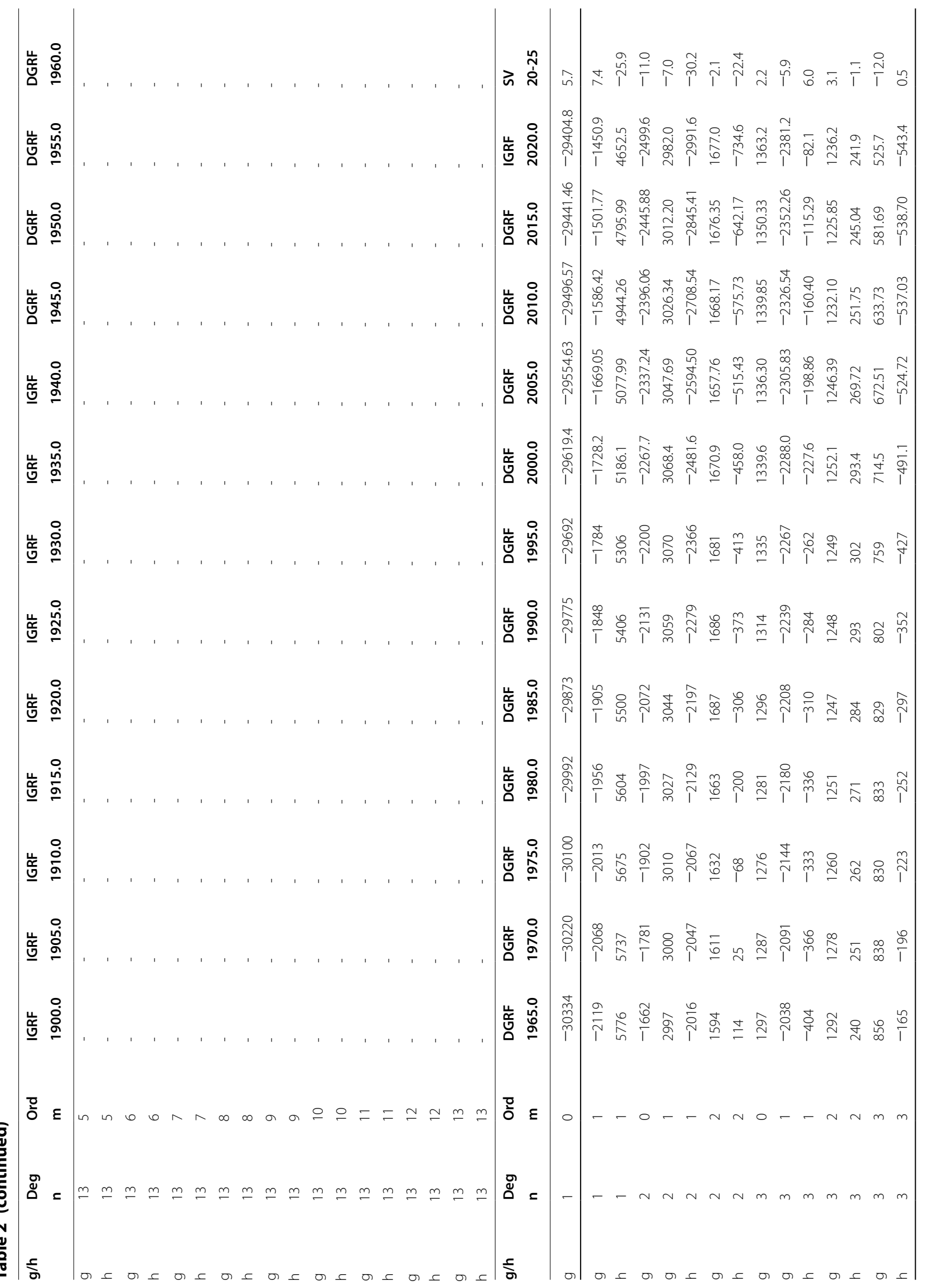




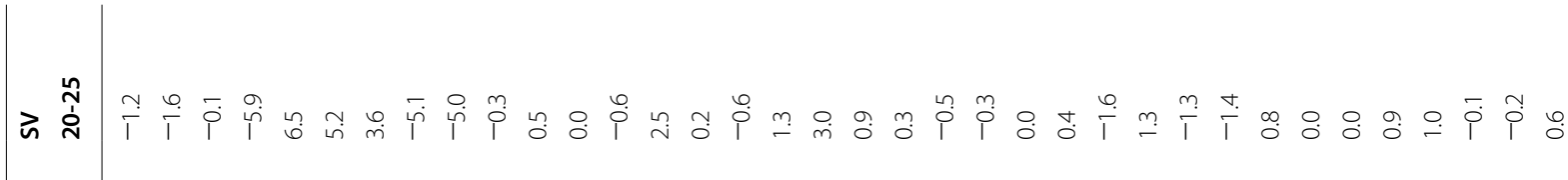

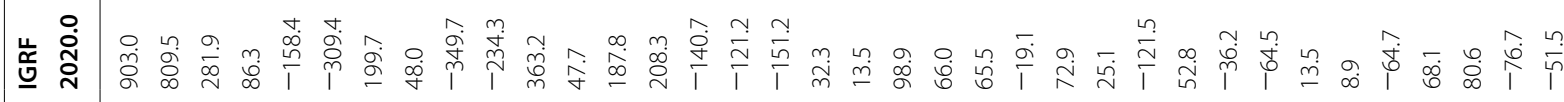

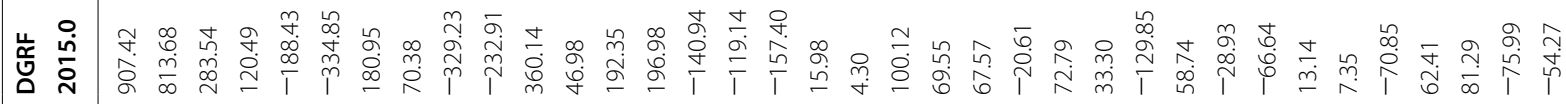

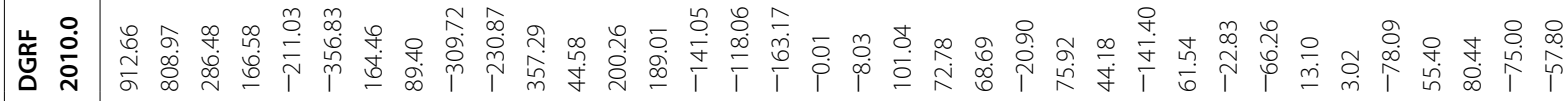

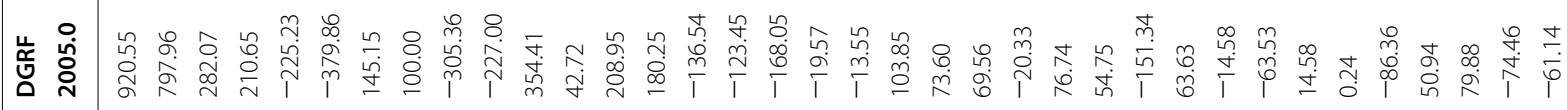

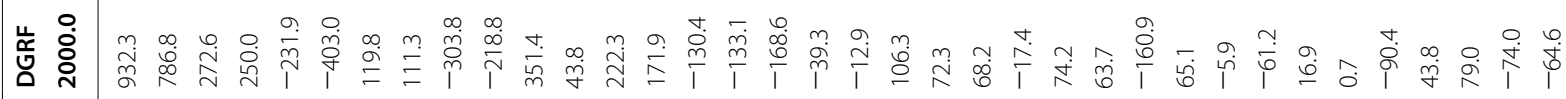
岕 离 崖 家

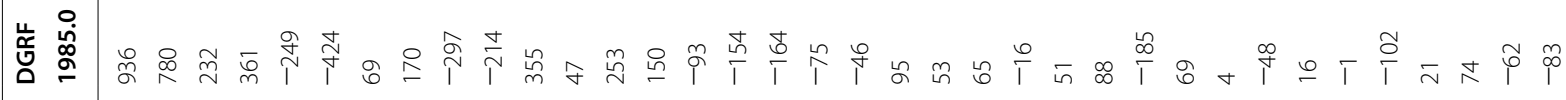
峞 品

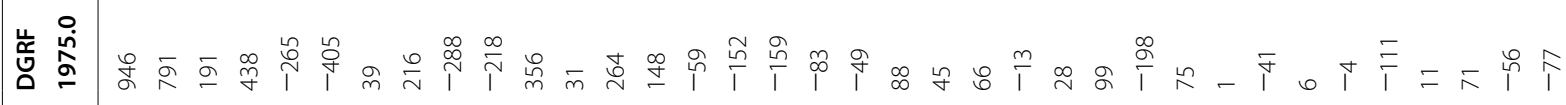

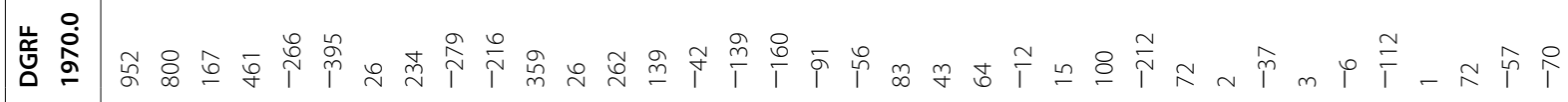

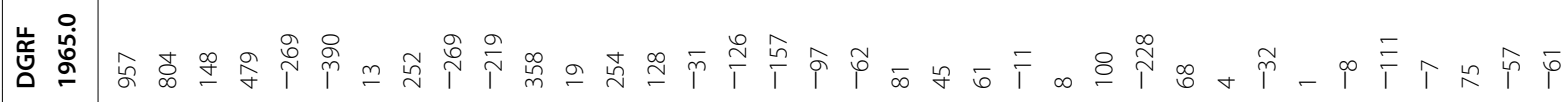

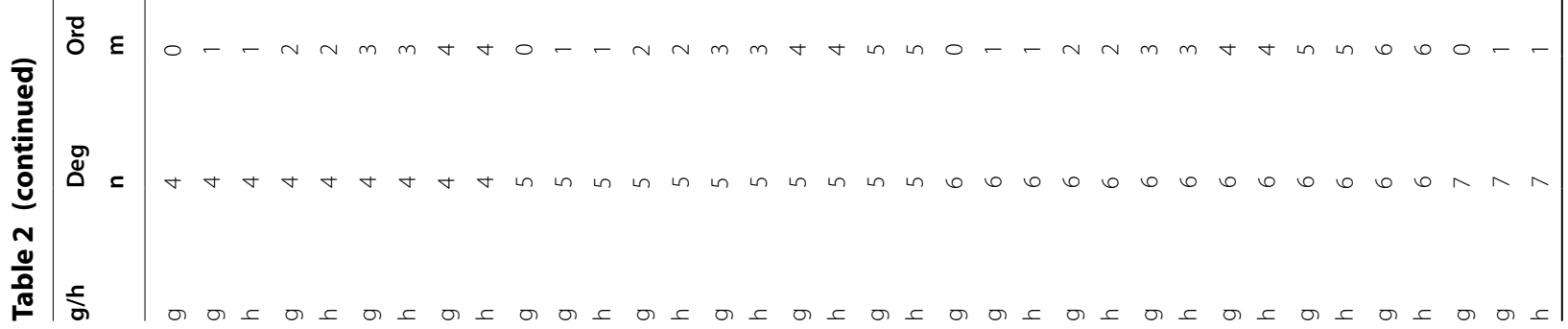




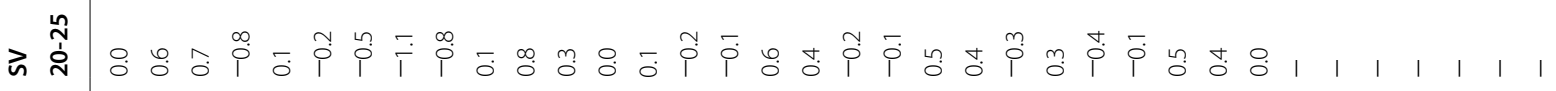
峁 定

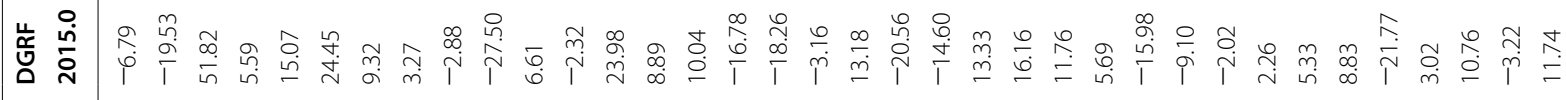

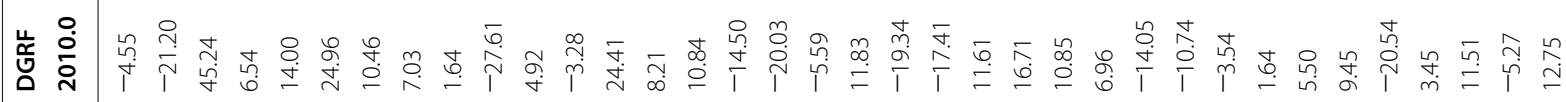

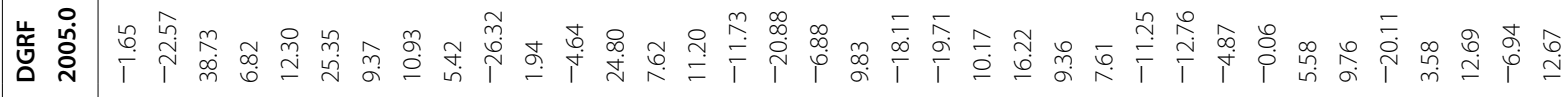

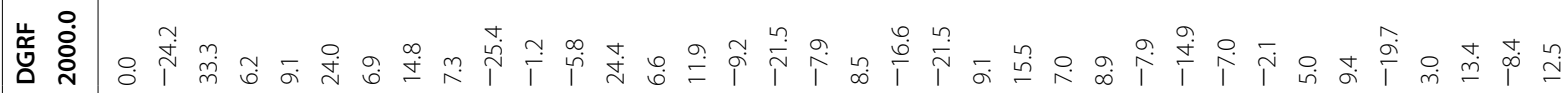

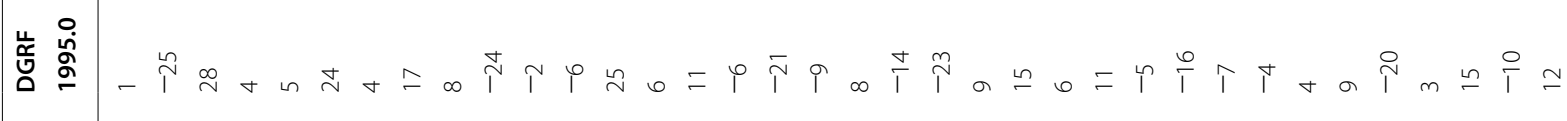
岕 京

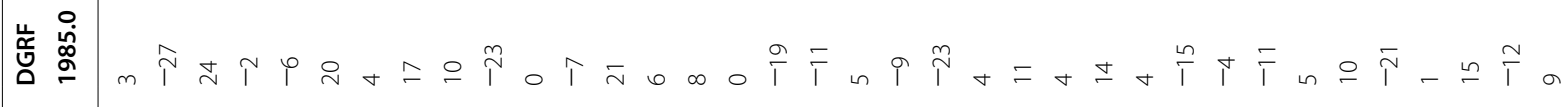

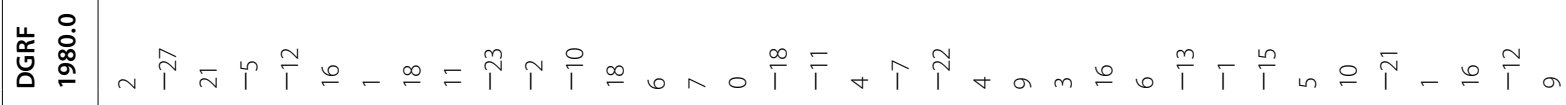

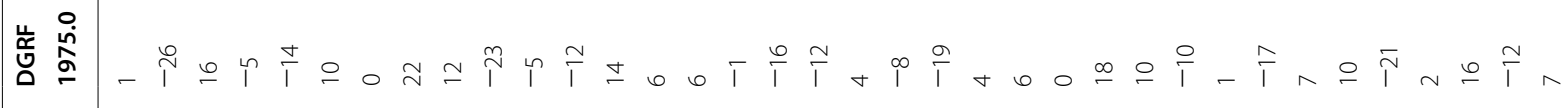
岕 号

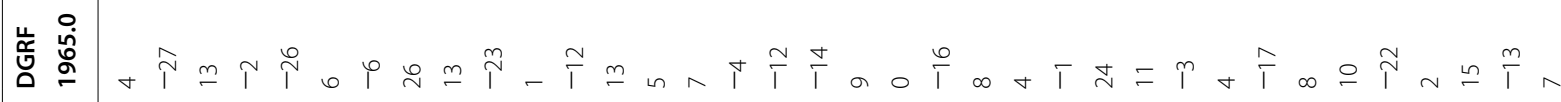

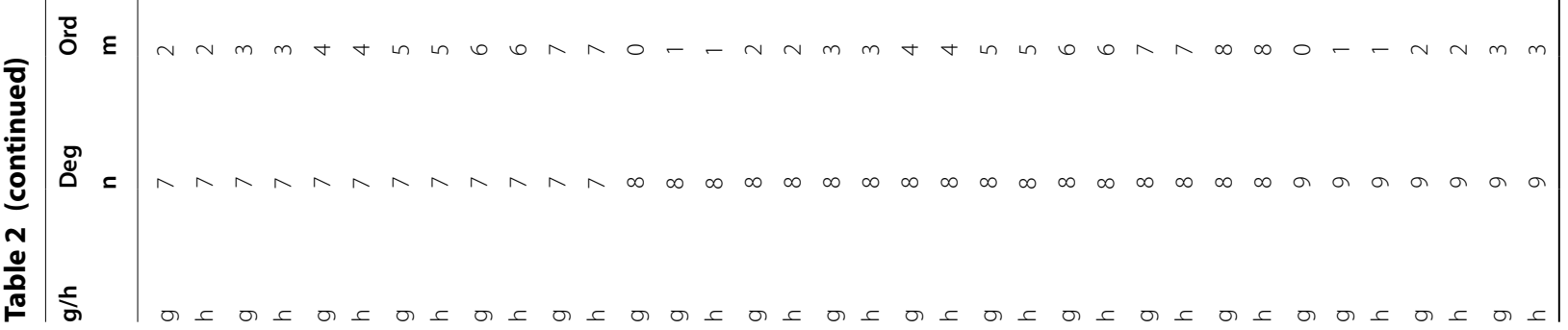




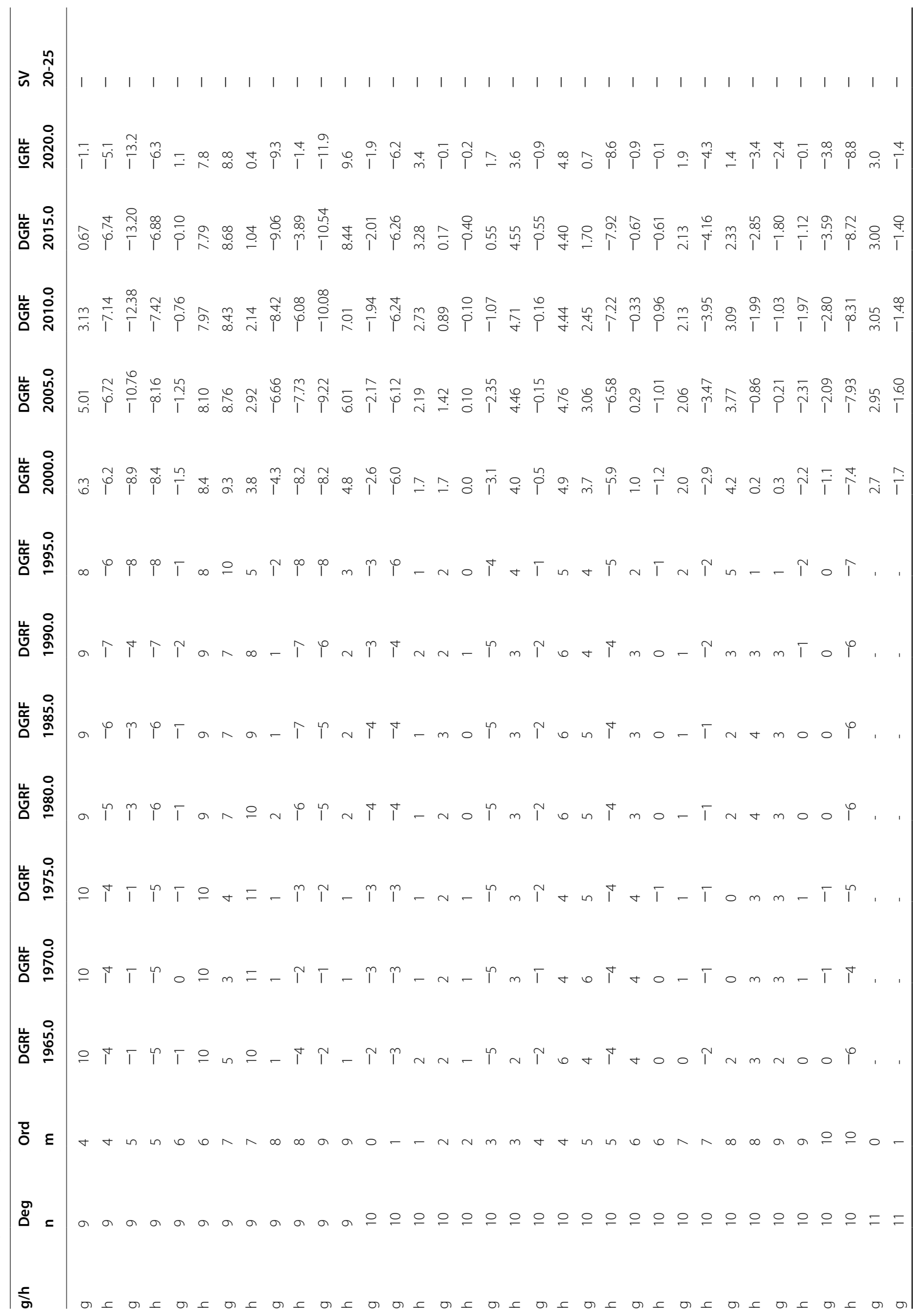




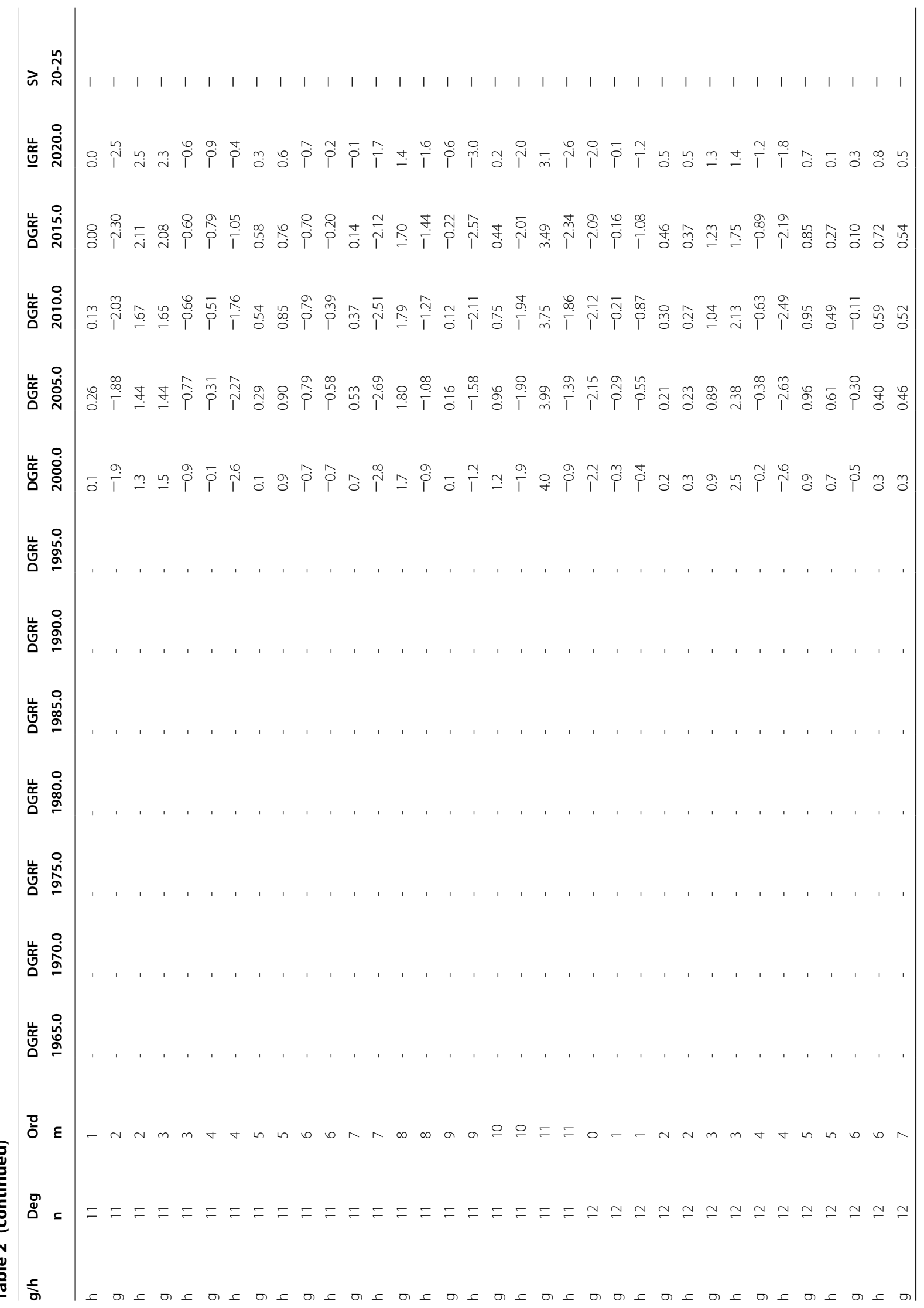




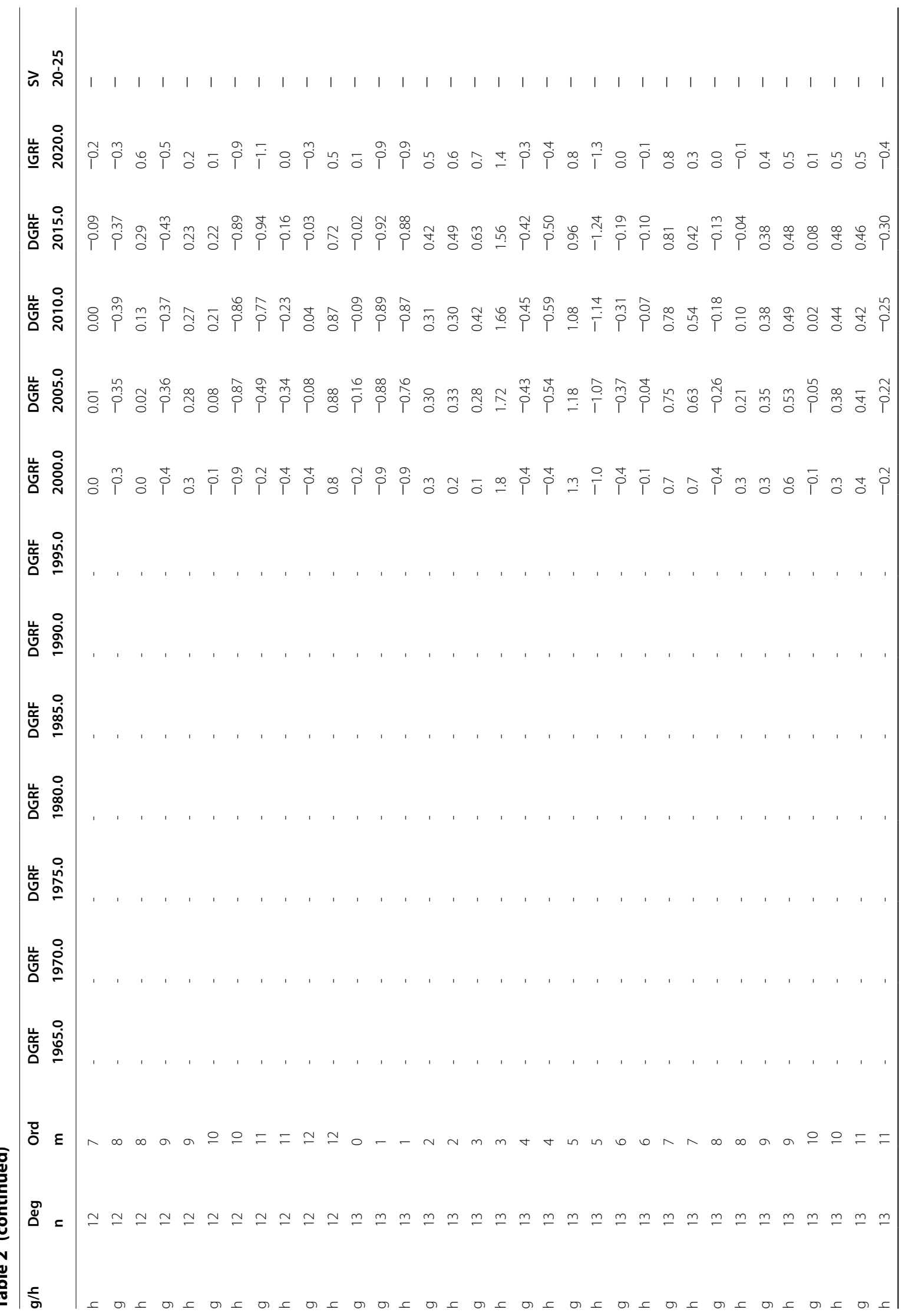




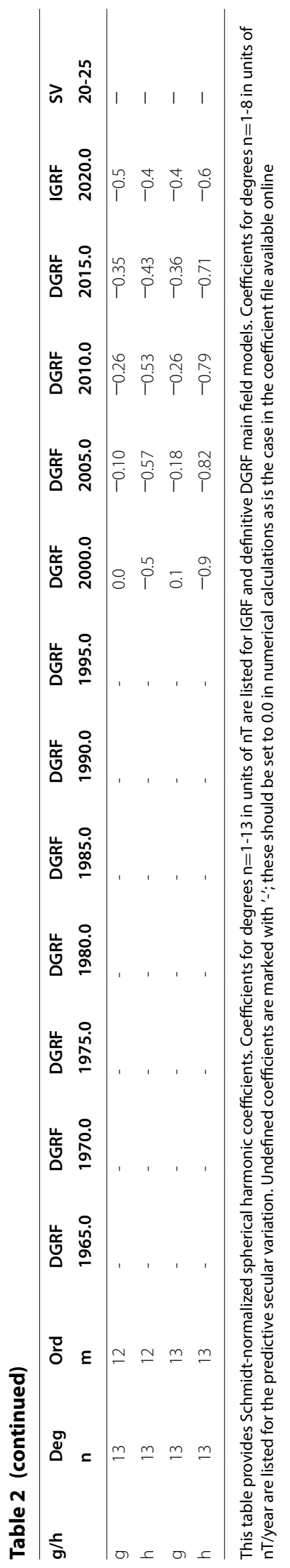

$\dot{g}_{n}^{m}\left(T_{t}\right), \dot{h}_{n}^{m}\left(T_{t}\right)$ represent the linear approximation to the change in the Gauss coefficients over the 5-year interval spanning $\left[T_{t}, T_{t}+5\right]$. They may be computed in units of nanoTesla per year (nT/year) as

$$
\begin{aligned}
& \dot{g}_{n}^{m}\left(T_{t}\right)=\frac{1}{5}\left(g_{n}^{m}\left(T_{t}+5\right)-g_{n}^{m}\left(T_{t}\right)\right), \\
& \dot{h}_{n}^{m}\left(T_{t}\right)=\frac{1}{5}\left(h_{n}^{m}\left(T_{t}+5\right)-h_{n}^{m}\left(T_{t}\right)\right) .
\end{aligned}
$$

The main field coefficients are not yet known for $T_{t}=2025$, and so for the final 5 years of model validity (2020 to 2025 for IGRF-13), the coefficients $\dot{g}_{n}^{m}(2020), \dot{h}_{n}^{m}(2020)$ are explicitly provided (see last column of Table 2) in units of nT/year. Details on the individual candidate secular variation forecasts and the procedure used to combine them into a final set of $\dot{g}_{n}^{m}(2020), \dot{h}_{n}^{m}$ (2020) may be found in Alken et al. (2020b) and references therein.

\section{The 13th generation IGRF}

In August 2017, during an IAGA V-MOD Working Group meeting held in Cape Town, South Africa, a task force of volunteer geomagnetic modelers was assembled to oversee the call for IGRF-13 candidate models and their evaluation. In March 2019, the task force issued an international call for three candidates:

- A DGRF main field model for the epoch 2015.0

- An IGRF main field model for the epoch 2020.0

- An IGRF linear secular variation model for the time period 2020.0 to 2025.0.

Fifteen teams representing over 30 international institutes responded to the call. The number of teams and institutions who participated in IGRF-13 exceeded that of any previous generation. The task force received 11 DGRF main field candidates for epoch 2015.0, 12 IGRF main field candidates for 2020.0, and 14 IGRF secular variation candidates for 2020.0-2025.0. Following recent IGRF conventions, the main field candidates for IGRF-13 describe the spatial variation of the field to a maximum spherical harmonic degree and order of 13 , while the secular variation candidates extend to a maximum degree and order of 8 . Each of the 15 teams was managed by a team leader from the lead institution, and many teams also included personnel from supporting institutions. The 15 lead institutions for IGRF-13, including references to their candidate model papers, are: (1) British Geological Survey (UK) (Brown et al. 2020); (2) Institute of Crustal Dynamics, China Earthquake Administration (China) (Yang et al. 2020); (3) Universidad Complutense de 
Madrid (Spain) (Pavón-Carrasco et al. 2020); (4) University of Colorado Boulder (USA) (Alken et al. 2020a); (5) Technical University of Denmark (Denmark) (Finlay et al. 2020); (6) GFZ German Research Centre for Geosciences (Germany) (Rother et al. 2020); (7) Institut de physique du globe de Paris (France) (Fournier et al. 2020; Vigneron et al. 2020; Ropp et al. 2020); (8) Institut des Sciences de la Terre (France) (Huder et al. 2020); (9) Pushkov Institute of Terrestrial Magnetism, Ionosphere and Radio Wave Propagation (Russia) (Petrov and Bondar 2020); (10) Kyoto University (Japan) (Minami et al. 2020); (11) University of Leeds (UK) (Metman et al. 2020); (12) Max Planck Institute for Solar System Research (Germany) (Sanchez et al. 2020); (13) NASA Goddard Space Flight Center (USA) (Sabaka et al. 2020; Tangborn et al. 2020); (14) University of Potsdam (Germany) (Baerenzung et al. 2020), and (15) Université de Strasbourg (France) (Wardinski et al. 2020). Some of the lead institutes listed above also acted as supporting institutions to other teams. The supporting institutes which are not listed above include: Geoscience Institute (Spain), Hebei GEO University (China), Institute of Earthquake Forecasting, China Earthquake Administration (China), Institute of Geophysics, China Earthquake Administration (China), Kyushu University (Japan), Nagoya University (Japan), National Space Science Center, Chinese Academy of Sciences (China), Observatori de l'Ebre (Spain), Observatorio Geofísico de Toledo (Spain), Real Observatorio Geofísico de la Armada (Spain), Space Research Institute of the Austrian Academy of Sciences (Austria), The Institute of Statistical Mathematics (Japan), Tokyo Institute of Technology (Japan), Université de Nantes (France), and University of Tokyo (Japan).

Data recorded by the Swarm satellite mission (FriisChristensen et al. 2006) and the ground observatory network (see Table 3) played a crucial role in the development of many of the IGRF-13 candidate models. Data from the Ørsted (Olsen et al. 2000), CHAMP (Reigber et al. 2002), SAC-C (Colomb et al. 2004), Cryosat-2, and CSES (Shen et al. 2018) missions were also used by some of the teams. The IGRF-13 task force voted to calculate the final main field models for epochs 2015.0 and 2020.0 as the medians of the Gauss coefficients of all the candidate models. The task force voted to use a robust Huber weighting in space to determine the final secular variation model for 2020.0 to 2025.0. Further details of the candidate models, the evaluation process, and the final model determination are provided in Alken et al. (2020b).

\section{IGRF-13 model coefficients and maps}

Table 2 lists the IGRF-13 spherical harmonic Gauss coefficients, which can be used with Eq. (1) to determine the geomagnetic potential (and vector geomagnetic field) anywhere on or above Earth's surface. This table serves as a published record of IGRF-13, which should allow users to ensure they use the correct model coefficients for a particular epoch compared with previous generations. The main field coefficients are given in units of $\mathrm{nT}$, and the predictive secular variation coefficients (last column) are given in units of nT/year. These coefficients are available in digital form from https://www.ngdc.noaa.gov/ IAGA/vmod/igrf.html along with software to compute magnetic field components at different times and spatial locations, in both geocentric and geodetic coordinate systems.

Figure 1 shows global maps of the IGRF-13 declination $(D)$, inclination $(I)$, and total field magnitude $(F)$ on Earth's surface at 2020 in Miller cylindrical projection. Taken together, these three quantities fully describe the vector magnetic field at Earth's surface. The green contour lines represent zero. For the declination component (top panel), these are the agonic lines on which a magnetic compass needle would point to true geographic north. For the inclination map (middle panel), the green contour line of zero inclination shows the magnetic dip equator, which approximately aligns with the geographic equator except for a large, well-known southward deviation over South America. The $F$ map (bottom panel) shows that the largest field intensities occur in Siberia in the northern hemisphere and in the Southern Ocean between Australia and Antarctic in the southern hemisphere. We also see a region of significantly weaker field (compared to an idealized dipole), centered over South America, which is known as the South Atlantic Anomaly. In this region, the inner Van Allen radiation belt comes closest to Earth's surface, which has important consequences for satellite instrumentation and human safety in low Earth orbit. Interestingly, a new second minimum is becoming more pronounced over the southern Atlantic. This feature is described in more detail in Rother et al. (2020) and Finlay et al. (2020) and was earlier reported by Terra-Nova et al. (2019).

Figure 2 shows the predicted average change of the $D, I$, and $F$ components on Earth's surface during the 2020 to 2025 interval from IGRF-13. At low and middle latitudes, the map of $d D / d t$ (top panel) predicts the largest declination changes in the South Atlantic Anomaly region and also in the polar regions, with northern polar declination changing more than in the southern polar region. The $d I / d t$ map (middle panel) predicts the largest changes over Brazil, where the magnetic dip equator has moved relatively rapidly over the past few decades. The features seen in $d F / d t$ (bottom panel) near South America predict a deepening and westward movement of the South Atlantic Anomaly, continuing a trend observed over the past century (Finlay et al. 2010a, Fig. 3). 
Table 3 Magnetic observatories contributing data used in the construction of IGRF-13

\begin{tabular}{|c|c|c|}
\hline Supporting agencies & Country & Observatory IAGA code \\
\hline Centre de Recherche en Astronomie, Astrophysique et Geophysique & Algeria & TAM \\
\hline Universidad Nacional de la Plata & Argentina & TRW \\
\hline Servicio Meteorologico Nacional & Argentina & $\mathrm{PIL}, \mathrm{ORC}$ \\
\hline \multirow[t]{2}{*}{ Geoscience Australia } & Australia & ASP, CKI, CNB, CSY, CTA, DVS \\
\hline & & GNA, GNG, KDU, LRM, MAW, MCQ \\
\hline Zentralanstalt für Meteorologie und Geodynamik & Austria & WIC \\
\hline National Academy of Sciences & Belarus & MNK \\
\hline Institut Royal Météorologique & Belgium & DOU, MAB \\
\hline CNPq-Observatorio Nacional & Brazil & VSS, TTB \\
\hline Academy of Sciences & Bulgaria & PAG \\
\hline \multirow[t]{2}{*}{ Geological Survey of Canada } & Canada & ALE, BLC, BRD, CBB, FCC, IQA \\
\hline & & MEA, OTT, RES, STJ, VIC,YKC \\
\hline Centro Meteorológico Regional Pacifico & Chile & IPM \\
\hline Academy of Sciences & China & BMT, SSH \\
\hline \multirow[t]{2}{*}{ China Earthquake Administration } & China & $\mathrm{CDP}, \mathrm{CNH}, \mathrm{GLM}, \mathrm{GZH}, \mathrm{KSH}, \mathrm{LZH}$ \\
\hline & & MZL, QGZ, QIX, QZH, THJ, WHN \\
\hline Instituto Geographico Agustin Codazzi & Columbia & FUQ \\
\hline University of Zagreb & Croatia & $\mathrm{LON}$ \\
\hline Academy of Sciences & Czech Republic & BDV \\
\hline Technical University of Denmark, DTU Space & Denmark & $\mathrm{BFE}, \mathrm{NAQ}, \mathrm{GDH}, \mathrm{THL}$ \\
\hline Addis Ababa University & Ethiopia & $\mathrm{AAE}$ \\
\hline Finnish Meteorological Institute & Finland & NUR \\
\hline Geophysical Observatory & Finland & SOD \\
\hline \multirow[t]{2}{*}{ Institut de Physique du Globe de Paris } & France & AAE, BOX, CLF, DLT, KOU, IPM \\
\hline & & LZH, MBO, PHU, PPT, TAM \\
\hline Ecole et Observatoire des Sciences de la Terre & France & AMS, CZT, DMC, DRV, PAF, TAN \\
\hline Institut de recherche pour le développement & France & $\mathrm{BNG}, \mathrm{MBO}$ \\
\hline Georgian Academy of Sciences & Georgia & TFS \\
\hline Universität München & Germany & FUR \\
\hline Alfred-Wegener-Institute for Polar Marine Research & Germany & VNA \\
\hline \multirow[t]{2}{*}{ GFZ German Research Centre for Geosciences } & Germany & ABG, BFO, GAN, HYD, KMH, MGD, NGK, PAG \\
\hline & & PET, SHE, SUA, TDC, TTB, VNA, VSS, WNG, YAK \\
\hline Universität Stuttgart and KIT & Germany & $\mathrm{BFO}$ \\
\hline Institute of Geology and Mineral Exploration & Greece & PEG \\
\hline Academy of Sciences & Hungary & NCK \\
\hline Mining and Geological Survey of Hungary & Hungary & THY \\
\hline University of Iceland & Iceland & LRV \\
\hline \multirow[t]{2}{*}{ Indian Institute of Geomagnetism } & India & ABG, JAI, NGP, PND, SIL \\
\hline & & SHL, TIR, UJJ, VSK \\
\hline National Geophysical Research Institute & India & $\mathrm{HYB}$ \\
\hline Meteorological and Geophysical Agency & Indonesia & KPG, PLR, TND, TUN \\
\hline Meteorological Service & Ireland & VAL \\
\hline Survey of Israel & Israel & AMT, BGY, ELT \\
\hline Instituto Nazionale di Geofisica e Vulcanologia & Italy & AQU, CTS, DMC \\
\hline Japan Coast Guard & Japan & HTY \\
\hline Japan Meteorological Agency & Japan & $\mathrm{CBI}, \mathrm{KAK}, \mathrm{KNY}, \mathrm{MMB}$ \\
\hline Geographical Survey Institute & Japan & ESA, KNZ, MIZ \\
\hline Institute of the lonosphere & Kazakhstan & AAA \\
\hline Korean Meteorological Administration & Rep of Korea & CYG \\
\hline
\end{tabular}


Table 3 (continued)

\begin{tabular}{|c|c|c|}
\hline Supporting agencies & Country & Observatory IAGA code \\
\hline Institut et Observatoire Géophysique d'Antananarivo & Madagascar & TAN \\
\hline Gan Meteorological Office & Maldives & GAN \\
\hline Direção Provincial de Recursos Minerais e Energia de Tete & Mozambique & LMM, NMP \\
\hline Instituto de Geofisica de UNAM & Mexico & TEO \\
\hline Institute of Geological and Nuclear Sciences & New Zealand & API, EYR, SBA \\
\hline University of Troms $\varnothing$ & Norway & BJN, DOB, TRO \\
\hline Instituto Geofisico del Peru & Peru & HUA \\
\hline Academy of Sciences & Poland & BEL, HLP, HRN \\
\hline Universidade de Coimbra & Portugal & $\mathrm{COI}$ \\
\hline Geological Survey of Romania & Romania & SUA \\
\hline AARI & Russia & VOS \\
\hline GC RAS & Russia & ARS, BOX, SPG \\
\hline IG UB RAS & Russia & ARS \\
\hline IKIR-RAS & Russia & $\mathrm{KHB}, \mathrm{MGD}, \mathrm{PET}$ \\
\hline IPGG SB RAS & Russia & NVS \\
\hline ISTP SB RAS & Russia & IRT \\
\hline SHICRA SB RAS & Russia & YAK \\
\hline Dept. of Agriculture, Forestry, Fisheries \& Meteorology & Samoa & API \\
\hline Geomagnetic College Grocka & Serbia \& Montenegro & GCK \\
\hline Slovenska Akademia Vied & Slovakia & $\mathrm{HRB}$ \\
\hline National Research Foundation & South Africa & HBK, HER, KMH, TSU \\
\hline Observatori de l'Ebre & Spain & EBR, LIV \\
\hline Real Instituto y Observatorio de la Armada & Spain & SFS \\
\hline Instituto Geográfico Nacional & Spain & GUI, SPT \\
\hline Sveriges Geologiska Undersökning & Sweden & ABK, LYC, UPS \\
\hline Swedish Institute of Space Physics & Sweden & $\mathrm{KIR}$ \\
\hline ETH Zurich & Switzerland & GAN \\
\hline Bŏgaziçi University & Turkey & IZN \\
\hline Academy of Sciences & Ukraine & AIA, LVV, KIV \\
\hline British Geological Survey & United Kingdom & ASC, ESK, HAD, JCO, KEP, LER, PST, SBL \\
\hline \multirow[t]{2}{*}{ US Geological Survey } & United States & BRW, BOU, BSL, CMO, DED, FRD, FRN \\
\hline & & GUA, HON, NEW, SIT, SJG, SHU, TUC \\
\hline Academy of Science and Technology & Vietnam & DLT, PHU \\
\hline
\end{tabular}

Figure 3 presents the positions of the geomagnetic poles and dip poles as given by IGRF-13 for 1900 to 2020 , and the predicted positions in 2025. The geomagnetic poles are calculated from the three dipole $(n=1)$ Gauss coefficients and correspond to where the magnetic dipole axis intersects a sphere of mean Earth radius $6371.2 \mathrm{~km}$. These poles are antipodal and are also known as centered dipole poles (Laundal and Richmond 2017, Eq. 14). The geomagnetic poles can be used to specify the relative orientation of Earth's magnetic field with respect to the Sun, and they are often used in magnetospheric studies for this purpose. The magnetic dip poles are defined as the locations where the main magnetic field as a whole is normal to Earth's surface, represented by the WGS84 reference ellipsoid. Equivalently, they can be defined as the locations where the magnetic field component tangent to the ellipsoid vanishes. Here, we use the full set of IGRF-13 coefficients to spherical harmonic degree $N$. Magnetic dip poles provide a key reference for local orientation when navigating on or close to Earth's surface at highlatitudes. For a perfect dipole field, the geomagnetic and dip poles would nearly coincide, but not exactly since the geomagnetic poles are defined with respect to a sphere of mean Earth radius, while the dip poles are defined with respect to the WGS84 ellipsoid. However, as can be seen in the figure, there are significant differences between the two due to the non-dipolar structure 

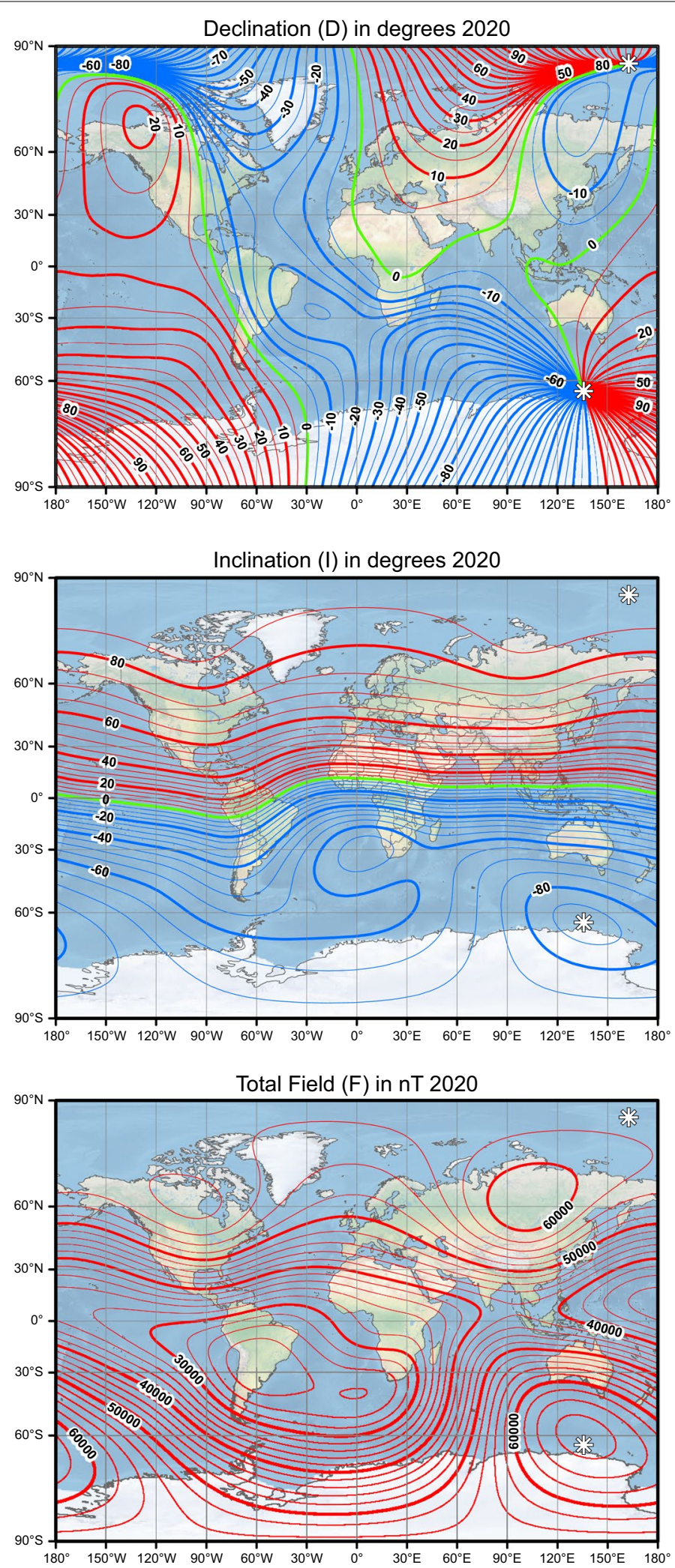

Fig. 1 Maps of declination (top), inclination (middle) and total field (bottom) at the WGS84 ellipsoid surface for epoch 2020. The zero contour is shown in green, positive contours in red, and negative contours in blue. White asterisks indicate locations of the magnetic dip poles. Projection is Miller cylindrical 


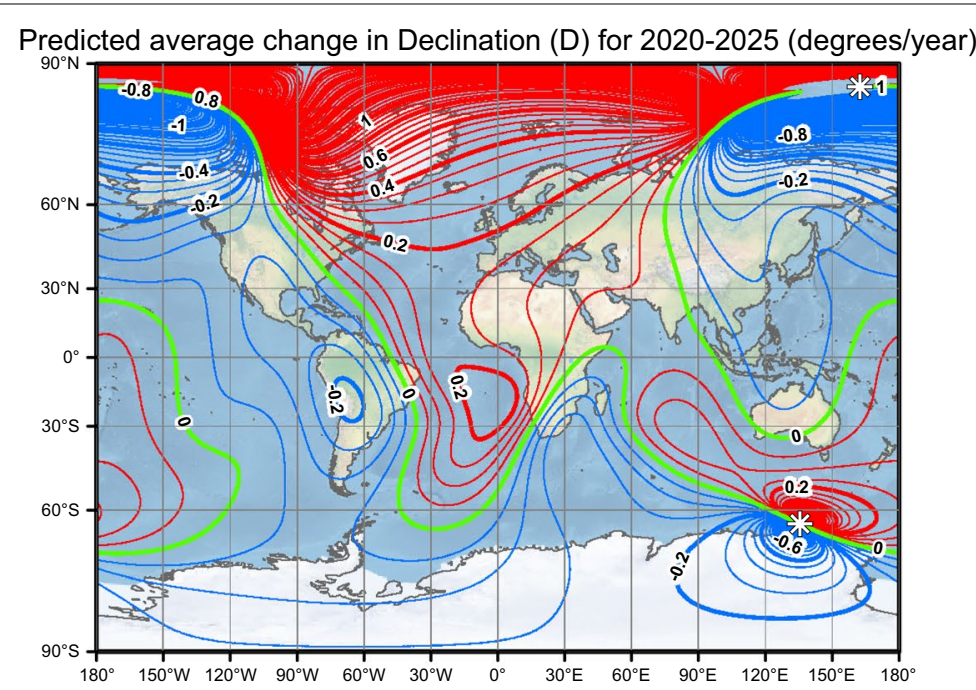

Predicted average change in Inclination (I) for 2020-2025 (degrees/year)

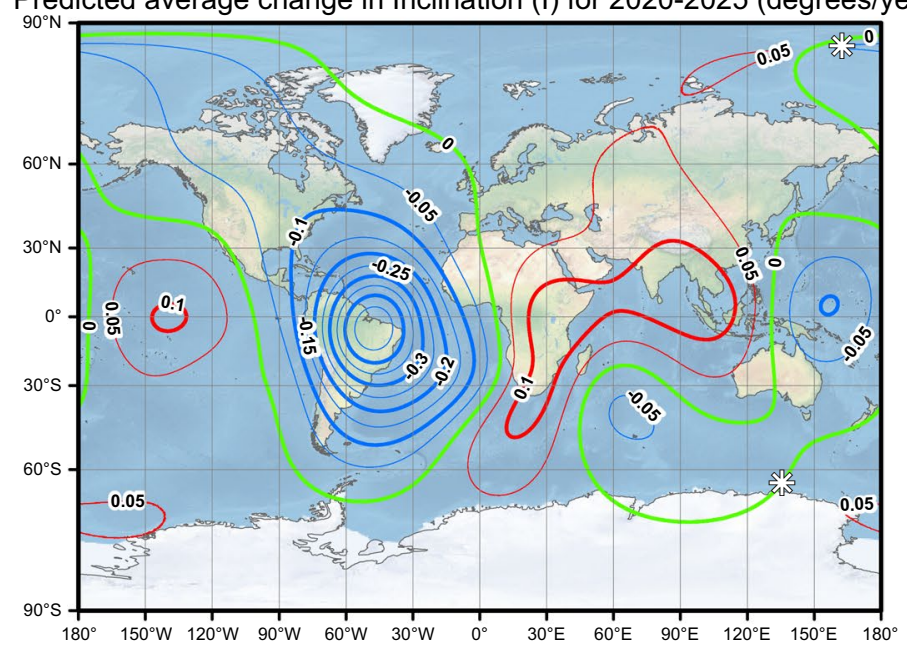

Predicted average change in Total Field (F) for 2020-2025 (nT/year)

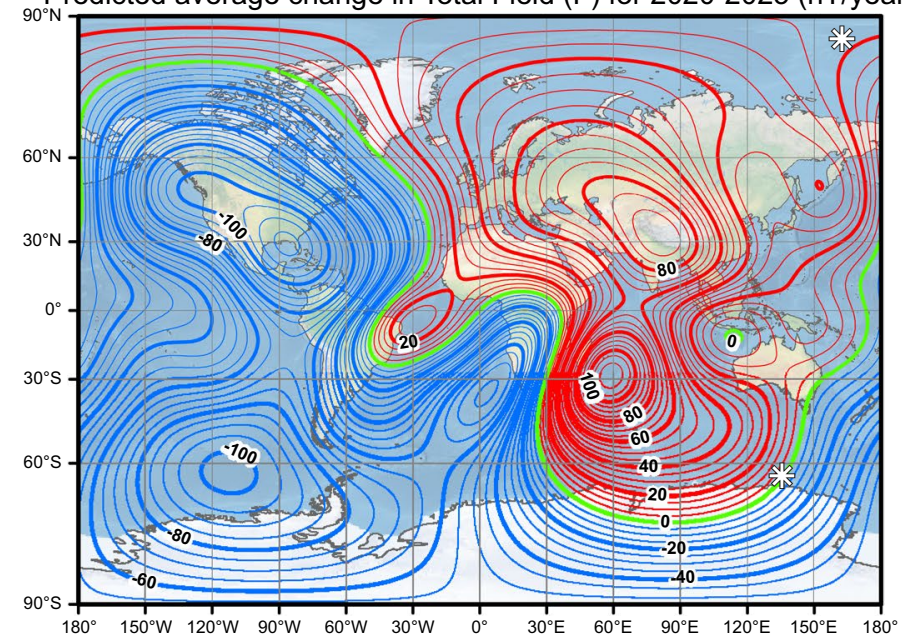

Fig. 2 Maps of predicted annual secular variation in declination (top), inclination (middle) and total field (bottom) at the WGS84 ellipsoid surface averaged over 2020 to 2025. The zero contour is shown in green, positive contours in red, and negative contours in blue. White asterisks indicate locations of the magnetic dip poles. Projection is Miller cylindrical 


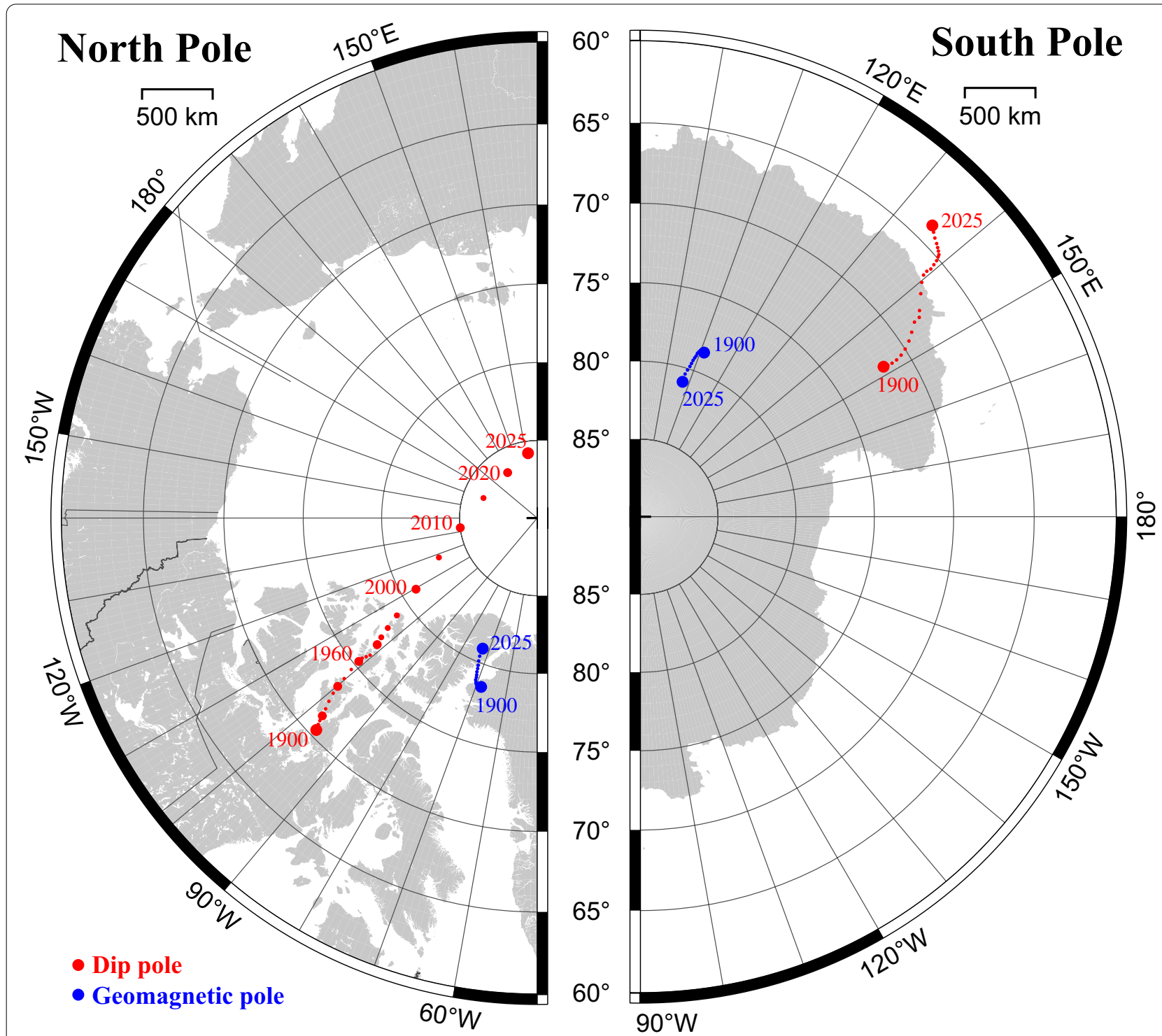

Fig. 3 Motion of the magnetic dip pole (red) and geomagnetic pole (blue) since 1900 from IGRF-13 in the northern hemisphere (left) and southern hemisphere (right). The scale provides an indication of distance on the WGS84 ellipsoid that is correct along lines of constant longitude and also along the middle lines of latitude shown. Note the left and right panels use different longitude ranges. The maps use stereographic projection. International and provincial boundaries are drawn in the left panel

of Earth's magnetic field. The geomagnetic and dip pole locations are provided in Table 4.

Figure 4 shows the speed of the two magnetic dip poles. The north magnetic dip pole experienced a strong acceleration from about 1960 to 2000, but has seen a modest deceleration over the past 20 years, peaking at $55.8 \mathrm{~km} /$ year in 2002.5 and slowing slightly to $50.6 \mathrm{~km} /$ year in 2017.5 . IGRF-13 forecasts a speed of $39.8 \mathrm{~km} /$ year in 2022.5 , however we caution that past IGRF forecasts contained significant errors (Finlay et al. 2010b). As an example, IGRF-12 predicted a north dip pole speed of $42.6 \mathrm{~km} /$ year for 2017.5 (Thébault et al. 2015), compared with the IGRF-13 value of $50.6 \mathrm{~km} /$ year. Uncertainties present in IGRF models are further discussed by Lowes (2000).

At Earth's surface in 2020, the contribution from the dipole terms $g_{1}^{0}, g_{1}^{1}, h_{1}^{1}$ accounts for over $93 \%$ of the power in the main geomagnetic field. It is therefore instructive to monitor the temporal change in the dipole moment, which is defined as: 
Table 4 Magnetic pole position since 1900 determined from IGRF-13 in units of degrees. Latitudes are provided in the WGS84 geodetic system

\begin{tabular}{|c|c|c|c|c|c|c|c|c|}
\hline \multirow[t]{2}{*}{ Epoch } & \multicolumn{2}{|c|}{ North dip pole } & \multicolumn{2}{|c|}{ South dip pole } & \multicolumn{2}{|c|}{ North geomagnetic pole } & \multicolumn{2}{|c|}{ South geomagnetic pole } \\
\hline & Latitude & Longitude & Latitude & Longitude & Latitude & Longitude & Latitude & Longitude \\
\hline 1900.0 & 70.46 & -96.19 & -71.72 & 148.32 & 78.68 & -68.79 & -78.68 & 111.21 \\
\hline 1905.0 & 70.66 & -96.48 & -71.46 & 148.54 & 78.68 & -68.75 & -78.68 & 111.25 \\
\hline 1910.0 & 70.79 & -96.72 & -71.15 & 148.64 & 78.66 & -68.72 & -78.66 & 111.28 \\
\hline 1915.0 & 71.03 & -97.03 & -70.80 & 148.54 & 78.64 & -68.57 & -78.64 & 111.43 \\
\hline 1920.0 & 71.34 & -97.38 & -70.41 & 148.20 & 78.63 & -68.38 & -78.63 & 111.62 \\
\hline 1925.0 & 71.79 & -97.99 & -69.99 & 147.62 & 78.62 & -68.27 & -78.62 & 111.73 \\
\hline 1930.0 & 72.27 & -98.68 & -69.52 & 146.79 & 78.60 & -68.26 & -78.60 & 111.74 \\
\hline 1935.0 & 72.80 & -99.33 & -69.06 & 145.76 & 78.57 & -68.36 & -78.57 & 111.64 \\
\hline 1940.0 & 73.30 & -99.87 & -68.57 & 144.59 & 78.55 & -68.51 & -78.55 & 111.49 \\
\hline 1945.0 & 73.93 & -100.24 & -68.15 & 144.44 & 78.55 & -68.53 & -78.55 & 111.47 \\
\hline 1950.0 & 74.64 & -100.86 & -67.89 & 143.55 & 78.55 & -68.85 & -78.55 & 111.15 \\
\hline 1955.0 & 75.18 & -101.42 & -67.19 & 141.50 & 78.54 & -69.16 & -78.54 & 110.84 \\
\hline 1960.0 & 75.30 & -101.03 & -66.70 & 140.23 & 78.58 & -69.47 & -78.58 & 110.53 \\
\hline 1965.0 & 75.63 & -101.34 & -66.33 & 139.53 & 78.60 & -69.85 & -78.60 & 110.15 \\
\hline 1970.0 & 75.88 & -100.97 & -66.02 & 139.40 & 78.66 & -70.18 & -78.66 & 109.82 \\
\hline 1975.0 & 76.15 & -100.64 & -65.74 & 139.52 & 78.76 & -70.47 & -78.76 & 109.53 \\
\hline 1980.0 & 76.91 & -101.68 & -65.42 & 139.35 & 78.88 & -70.76 & -78.88 & 109.24 \\
\hline 1985.0 & 77.40 & -102.61 & -65.13 & 139.18 & 79.04 & -70.90 & -79.04 & 109.10 \\
\hline 1990.0 & 78.10 & -103.69 & -64.91 & 138.90 & 79.21 & -71.13 & -79.21 & 108.87 \\
\hline 1995.0 & 79.04 & -105.29 & -64.79 & 138.73 & 79.39 & -71.42 & -79.39 & 108.58 \\
\hline 2000.0 & 80.97 & -109.64 & -64.66 & 138.30 & 79.61 & -71.57 & -79.61 & 108.43 \\
\hline 2005.0 & 83.19 & -118.22 & -64.55 & 137.85 & 79.82 & -71.81 & -79.82 & 108.19 \\
\hline 2010.0 & 85.02 & -132.84 & -64.43 & 137.32 & 80.09 & -72.21 & -80.09 & 107.79 \\
\hline 2015.0 & 86.31 & -160.34 & -64.28 & 136.60 & 80.38 & -72.61 & -80.38 & 107.39 \\
\hline 2020.0 & 86.49 & 162.87 & -64.08 & 135.87 & 80.65 & -72.68 & -80.65 & 107.32 \\
\hline 2025.0 & 85.78 & 138.06 & -63.85 & 135.06 & 80.90 & -72.64 & -80.90 & 107.36 \\
\hline
\end{tabular}

$$
M(t)=\frac{4 \pi}{\mu_{0}} a^{3} \sqrt{g_{1}^{0}(t)^{2}+g_{1}^{1}(t)^{2}+h_{1}^{1}(t)^{2}}
$$

Figure 5 presents the change in the dipole moment of the geomagnetic field since 1900 as predicted by IGRF13 (red). We see a clear downward trend in the dipole strength since the beginning of the last century, which is continued in 2020 and also in the forecast for 2025. This steady downward trend extends back at least as far as 1600 (Merrill et al. 1996; Constable and Korte 2015), although archeomagnetic and paleomagnetic records have revealed much lower dipole moments thousands of years in the past (Panovska et al. 2019). Due to sparsity of data, archeomagnetic and paleomagnetic studies often estimate the dipole strength along the rotation axis, ignoring the off-axis terms $g_{1}^{1}, h_{1}^{1}$. This so-called axial dipole moment is defined as $M_{A}(t)=4 \pi a^{3}\left|g_{1}^{0}(t)\right| / \mu_{0}$ and is shown in blue in the figure.

\section{IGRF-13 online data products}

Further general information about IGRF: https://www. ngdc.noaa.gov/IAGA/vmod/igrf.html

Coefficients of IGRF-13 in ASCII format: https://www. ngdc.noaa.gov/IAGA/vmod/coeffs/igrf13coeffs.txt

Fortran software to compute magnetic field components from coefficients: https://www.ngdc.noaa.gov/ IAGA/vmod/igrf13.f

Linux C software to compute magnetic field components from coefficients: https://www.ngdc.noaa.gov/ IAGA/vmod/geomag70_linux.tar.gz

Windows $\mathrm{C}$ software to compute magnetic field components from coefficients: https://www.ngdc.noaa.gov/ IAGA/vmod/geomag70_windows.zip

Python software to compute magnetic field components from coefficients: https://www.ngdc.noaa.gov/ IAGA/vmod/pyIGRF.zip

Online calculation of magnetic field components for IGRF-13: https://www.ngdc.noaa.gov/geomag/calculator s/magcalc.shtml and http://geomag.bgs.ac.uk/data_servi 


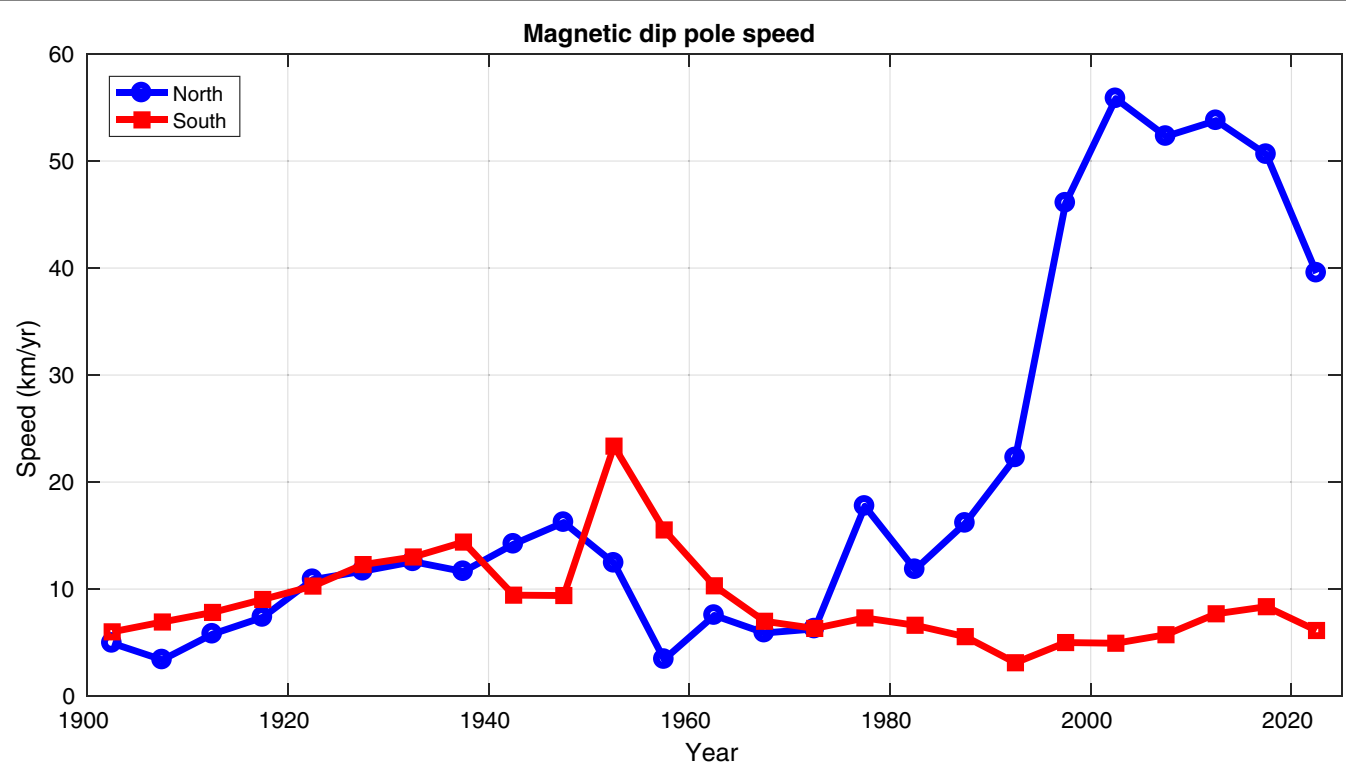

Fig. 4 Average speed of the magnetic dip poles over each 5-year epoch, plotted at the midpoint between epochs (i.e., the speed over 2015 -2020 is shown at 2017.5). The value for 2020-2025 is a forecast

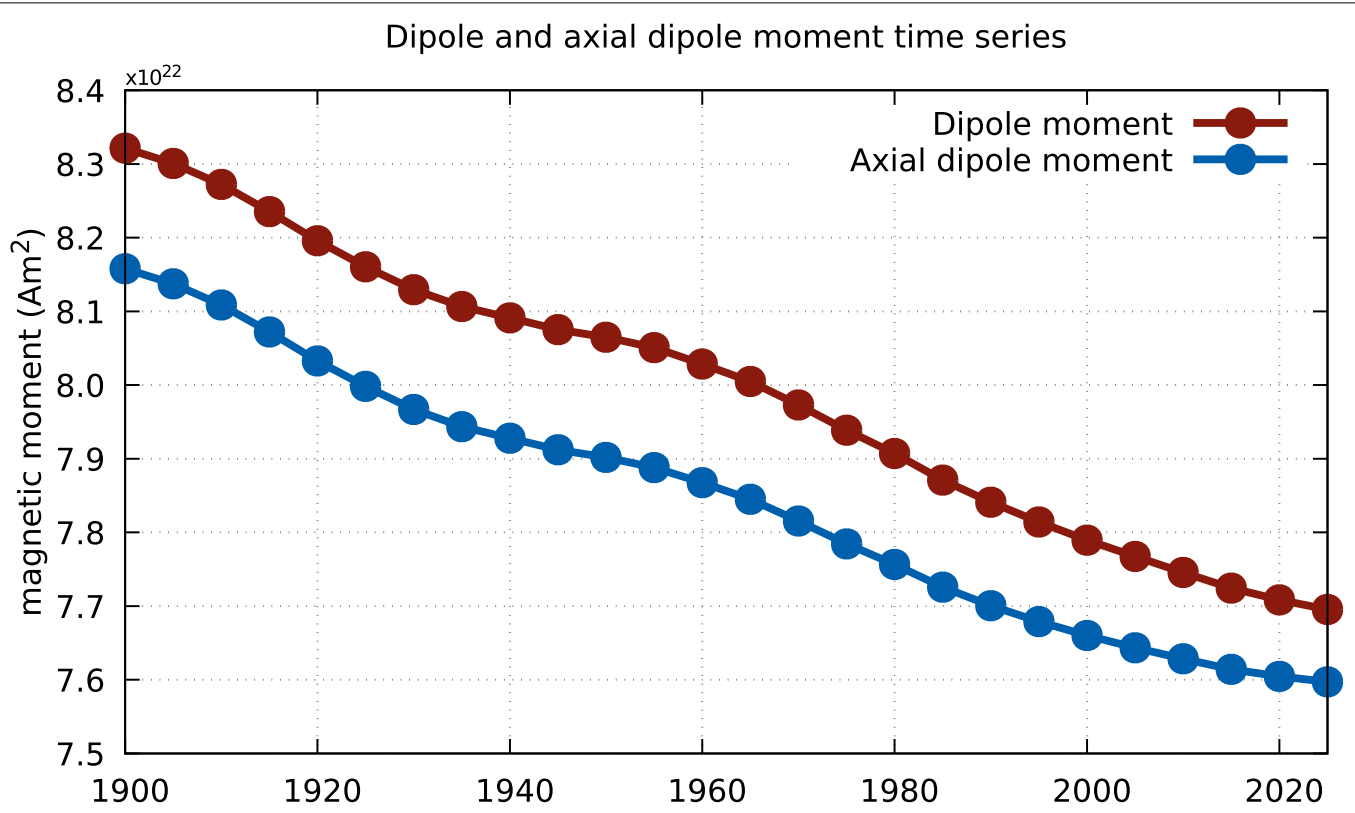

Fig. 5 Dipole and axial dipole moment time series derived from IGRF-13. The value for 2025 is a forecast

ce/models_compass/igrf_calc.html and http://wdc.kugi. kyoto-u.ac.jp/igrf/point/index.html

Archive of previous generations of IGRF: https://www. ngdc.noaa.gov/IAGA/vmod/igrf_old_models.html

Candidate models contributing to IGRF-13 and task force evaluation reports: https://www.ngdc.noaa.gov/ IAGA/vmod/IGRF13/

\section{Acknowledgements}

The European Space Agency (ESA) is gratefully acknowledged for providing access to the Swarm magnetic field data and for making it possible for IPGP and CEA-Léti to derive the additional ASM-V experimental data from the CNES funded ASM instrument, all used in this work. The China National Space Administration and the China Earthquake Administration are acknowledged for providing access to CSES magnetometer data. The results presented in this paper rely on data collected at magnetic observatories. We thank the national institutes that support them and INTERMAGNET for promoting high standards of magnetic observatory practice (www.intermagnet.org). 


\begin{abstract}
Authors' contributions
P. Alken is chair of the IAGA DIV V-MOD (2019-2023) and initiated, coordinated and organized the call and delivery of the 13th generation of the IGRF. E. Thébault is former chair (2015-2019). C. Beggan is presently co-chair (2019-2023). PA, ET and CDB wrote the manuscript based on the analyses of the contributing co-authors. All other authors contributed modeling results and/or detailed technical analyses for IGRF-13. All authors have read and approved the final manuscript.

\section{Funding}

The Swarm and Cryosat-2 missions are supported by the European Space Agency (ESA). The Ørsted mission was made possible by extensive support from the Danish government, NASA, ESA, CNES, DARA, and the Thomas B. Thriges Foundation. The CHAMP mission was sponsored by the Space Agency of the German Aerospace Center (DLR) through funds of the Federal Ministry of Economics and Technology, following a decision of the German Federal Parliament (grant code 50EE0944). The SAC-C mission was made possible by a collaboration between the Comisión Nacional de Actividades Espaciales (CONAE), NASA/JPL, and the Danish Space Research Institute. The CSES mission is funded by the China National Space Administration (CNSA) and the China Earthquake Administration (CEA). The international network of geomagnetic observatories is supported by numerous institutes, staff, and INTERMAGNET. The French contribution to this work was supported by the French Centre National des Etudes Spatiales (CNES) in the framework of the program "Exploitation de la mission satellitaire européenne Swarm."
\end{abstract}

\begin{abstract}
Availability of data and materials
Swarm and Cryosat-2 data are available from https://earth.esa.int/web/guest /swarm/data-access. CHAMP data can be obtained from http://isdc.gfz-potsd am.de. Ørsted and SAC-C data are available from https://www.space.dtu.dk/ english/research/scientific_data_and_models/magnetic_satellites. CSES data is available from http://www.leos.ac.cn. INTERMAGNET data is available from https://www.intermagnet.org.
\end{abstract}

\section{Competing interests}

The authors declare that they have no competing interests.

\section{Author details}

${ }_{1}$ Cooperative Institute for Research in Environmental Sciences, University of Colorado Boulder, 325 Broadway, E/NE42, Boulder, CO 80305, USA. ${ }^{2}$ NOAA National Centers for Environmental Information, Boulder, CO, USA. ${ }^{3}$ Laboratoire de Planétologie et Géodynamique, UMR 6112, Université de Nantes, Université d'Angers, CNRS, Nantes, France. ${ }^{4}$ British Geological Survey, The Lyell Centre, Research Avenue South, Edinburgh EH14 4AP, UK. ${ }^{5}$ Division of Geomagnetism, DTU Space, Technical University of Denmark, Centrifugevej 356, Kongens Lyngby 2800, Denmark. ${ }^{6}$ Université de Paris, Institut de Physique du Globe de Paris, CNRS, 75005 Paris, France. ${ }^{7}$ Univ. Grenoble Alpes, Univ. Savoie Mont Blanc, CNRS, IRD, IFSTTAR, ISTerre, 38000 Grenoble, France. ${ }^{8}$ School of Earth and Environment, University of Leeds, Leeds LS2 9JT, UK. ${ }^{9}$ University of Newcastle, Newcastle upon Tyne NE1 7RU, UK. ${ }^{10}$ GFZ German Research Centre for Geosciences, Telegrafenberg, 14473 Potsdam, Germany. ${ }^{11}$ Division of Earth and Planetary Sciences, Graduate School of Science, Kyoto University, Kitashirakawa Oiwake-cho, Sakyo-ku, Kyoto 606-8502, Japan. ${ }^{12}$ Institut de Physique du Globe de Strasbourg, Université de Strasbourg/EOST, CNRS, UMR 7516, Strasbourg, France. ${ }^{13}$ Institute of Crustal Dynamics, China Earthquake Administration, Beijing, China. ${ }^{14}$ State Key Laboratory of Space Weather, National Space Science Center, Chinese Academy of Sciences, Beijing 100190, China. ${ }^{15}$ Space Research Institute, Austrian Academy of Sciences, Schmiedlstraße 6, Graz, Austria. ${ }^{16}$ CEA-Leti, Minatec Campus, Grenoble, France. ${ }^{17}$ Pushkov Institute of Terrestrial Magnetism, lonosphere and Radio Wave Propagation, Kaluzhskoe Hwy 4, Moscow, Russia. ${ }^{18}$ Earthquake and Volcano Research Center, Graduate School of Environmental Studies, Nagoya University, D2-2, Furo-cho, Chikusa-ku, Nagoya, Aichi 464-8601, Japan. ${ }^{19}$ Department of Statistical Modeling, The Institute of Statistical Mathematics, 10-3 Midori-cho, Tachikawa, Tokyo 190-8562, Japan. ${ }^{20}$ Department of Planetology, Graduate School of Science, Kobe University, 1-1, Rokkodai-cho, Nada-ku, Kobe, Hyogo 657-8501, Japan. ${ }^{21}$ Max Planck Institute for Solar System Research, Justus-von-Liebig-Weg 3, 37077 Göttingen, Germany. ${ }^{22}$ University of Potsdam, Am Neuen Palais 10, Potsdam, Germany. ${ }^{23}$ NASA/Goddard Space Flight Center, Greenbelt, MD, USA. ${ }^{24}$ Universidad Complutense de Madrid, Madrid, Spain. ${ }^{25}$ Geoscience Institute IGEO, Madrid, Spain. ${ }^{26}$ Observatori de I'Ebre
(OE), Univ. Ramon Llull - CSIC, Roquetes, Spain. ${ }^{27}$ Centre National d'Etudes Spatiales, Paris, France. ${ }^{28}$ Institute of Geophysics, Department of Earth Sciences, ETH Zurich, Sonneggstrasse 5, Zurich 8092, Switzerland.

\section{Appendix 1: World data system} WORLD DATA SERVICE FOR GEOPHYSICS,
BOULDER

NOAA National Centers for Environmental Information

325 Broadway, E/NE42, Boulder, CO, 80305-3328, UNITED STATES OF AMERICA

TEL: +1 3034975480

FAX: +1 3034976513

EMAIL: geomag.models@noaa.gov

INTERNET: https://www.ngdc.noaa.gov

\section{WORLD DATA CENTER FOR GEOMAGNETISM, COPENHAGEN}

Technical University of Denmark, DTU Space, Centrifugevej, Building 356, DK 2800, Kgs. Lyngby, DENMARK

TEL: +45 45259713

FAX: +45 45259701

EMAIL: anna@space.dtu.dk

INTERNET: http://www.space.dtu.dk/English/Resea rch/Scientific_data_and_models

WORLD DATA CENTRE FOR GEOMAGNETISM, EDINBURGH

British Geological Survey

The Lyell Centre

Edinburgh, EH14 4AP

UNITED KINGDOM

TEL: +441316671000

EMAIL: wdcgeomag@bgs.ac.uk

INTERNET: http://www.wdc.bgs.ac.uk

WORLD DATA CENTER FOR GEOMAGNETISM, KYOTO

Data Analysis Center for Geomagnetism and Space Magnetism

Graduate School of Science, Kyoto University

Kitashirakawa-Oiwake Cho, Sakyo-ku

Kyoto, 606-8502, JAPAN

TEL: +8175753 3929

FAX: +81757227884

EMAIL: toh@kugi.kyoto-u.ac.jp

INTERNET: http://wdc.kugi.kyoto-u.ac.jp 
WORLD DATA CENTER FOR SOLID EARTH PHYSICS, MOSCOW

Geophysical Center of the Russian Academy of Sciences

Molodezhnaya, 3

Moscow, 119296, RUSSIA

TEL: +7 4959305649

FAX: +7 4959300506

EMAIL: wdcsep@wdcb.ru

INTERNET: http://www.wdcb.ru/sep/index.html

\section{WORLD DATA CENTRE FOR GEOMAGNETISM, MUMBAI \\ Indian Institute of Geomagnetism \\ New Panvel(W), Navi Mumbai, 410 218, INDIA \\ TEL: +9122 27480766 \\ FAX: +9122 27480762 \\ EMAIL: wdc@iigs.iigm.res.in \\ INTERNET: http://wdciig.res.in}

Received: 11 May 2020 Accepted: 3 October 2020

Published online: 11 February 2021

\section{References}

Alken P, Chulliat A, Nair M (2020a) NOAA/NCEl and University of Colorado candidate models for IGRF-13. Earth Planets Space. https://doi.org/10.1186/ s40623-020-01313-z

Alken P, Thébault E, Beggan C, Aubert J, Baerenzung J, Brown W, Califf S, Chulliat A, Cox G, Finlay CC, Fournier A, Gillet N, Hammer MD, Holschneider M, Hulot G, Korte M, Lesur V, Livermore P, Lowes F, Macmillan S, Nair M, Olsen N, Ropp G, Rother M, Schnepf NR, Stolle C, Toh H, Vervelidou F, Vigneron P, Wardinski I (2020b) Evaluation of candidate models for the 13th International Geomagnetic Reference Field. Earth Planets Space. https://doi. org/10.1186/s40623-020-01281-4

Baerenzung J, Holschneider M, Wicht J, Lesur V, Sanchez S (2020) The Kalmag model as a candidate for IGRF-13. Earth Planets Space. https://doi. org/10.1186/s40623-020-01295-y

Barraclough DR (1987) International geomagnetic reference field: the fourth generation. Phys Earth Planet Interiors 48(3):279-292. https://doi. org/10.1016/0031-9201(87)90150-6

Barraclough DR, Mundt W, Barker FS, Barton CE, Golovkov VP, Hood PJ, Lowes FJ, Peddie NW, Gui-zhong Q, Srivastava SP, Winch DE, Yukutake T, Zidarov DP, Chen-chang A, Estes RH, Kerridge DJ, Langel RA, Quinn JM, Sabaka TJ, Verhoef J (1987) International Geomagnetic Reference Field Revision 1987. J Geomagnetism Geoelectricity 39(12):773-779. https://doi. org/10.5636/jgg.39.773

Barton CE (1997) International geomagnetic reference field: The seventh generation. J Geomagnetism Geoelectricity 49(2-3):123-148. https://doi. org/10.5636/jgg.49.123

Brown W, Beggan CD, Cox G, Macmillan S (2020) The BGS candidate models for IGRF-13 with a retrospective analysis of IGRF-12 secular variation forecasts. Earth Planets Space. https://doi.org/10.1186/s40623-020-01301-3

Cain JC, Cain SJ (1971) Derivation of the International Geomagnetic Reference Field IGRF(10/68). Tech. Rep. D-6237, NASA

Colomb F, Alonso C, Hofmann C, Nollmann I (2004) SAC-C mission, an example of international cooperation. Adv Space Res 34(10):2194-2199. https:// doi.org/10.1016/j.asr.2003.10.039
Constable C, Korte M (2015) Centennial to millennial-scale geomagnetic field variations. In: Schubert G (ed) Treatise on Geophysics, vol 5, 2nd edn. Amsterdam, Elsevier. pp 309-341

Finlay CC, Maus S, Beggan CD, Bondar TN, Chambodut A, Chernova TA, Chulliat A, Golovkov VP, Hamilton B, Hamoudi M, Holme R, Hulot G, Kuang W, Langlais B, Lesur V, Lowes FJ, Lühr H, Macmillan S, Mandea M, McLean S, Manoj C, Menvielle M, Michaelis I, Olsen N, Rauberg J, Rother M, Sabaka TJ, Tangborn A, Tøffner-Clausen L, Thébault E, Thomson AWP, Wardinski I, Wei Z, Zvereva TI (2010a) International Geomagnetic Reference Field: the eleventh generation. Geophys J Int 183(3):1216-1230. https://doi. org/10.1111/j.1365-246X.2010.04804.x, https://academic.oup.com/gji/ article-pdf/183/3/1216/1785065/183-3-1216.pdf

Finlay CC, Maus S, Beggan CD, Hamoudi M, Lowes FJ, Olsen N, Thébault E (2010b) Evaluation of candidate geomagnetic field models for IGRF-11. Earth Planets Space 62(10):8

Finlay CC, Kloss C, Olsen N, Hammer M, Tøffner-Clausen L, Grayver A, Kuvshinov A (2020) The CHAOS-7 geomagnetic field model and observed changes in the South Atlantic Anomaly. Earth Planets Space. https://doi. org/10.1186/s40623-020-01252-9

Fournier A, Aubert J, Lesur V, Ropp G (2020) A secular variation candidate model for IGRF-13 based on Swarm data and ensemble inverse geodynamo modelling. Earth Planets Space. https://doi.org/10.1186/s4062 3-020-01309-9

Friis-Christensen E, Lühr H, Hulot G (2006) Swarm: a constellation to study the Earth's magnetic field. Earth Planets Space 58(4):351-358

Huder L, Gillet N, Finlay CC, Hammer MD, Tchoungui H (2020) COV-OBS.x2: 180 yr of geomagnetic field evolution from ground-based and satellite observations. Earth Planets Space. https://doi.org/10.1186/s40623-020-01194-2

IAGA Division I Study Group (1975) International Geomagnetic Reference Field 1975. J Geomagnetism Geoelectricity 27(5):437-439. https://doi. org/10.5636/jgg.27.437

Langel RA (1992) International geomagnetic reference field: the sixth generation. J Geomagnetism Geoelectricity 44(9):679-707. https://doi. org/10.5636/jgg. 44.679

Langel RA, Barraclough DR, Kerridge DJ, Golovkov VP, Sabaka TJ, Estes RH (1988) Definitive IGRF Models for 1945, 1950, 1955, and 1960. J Geomagnetism Geoelectricity 40(6):645-702. https://doi.org/10.5636/jgg.40.645

Laundal KM, Richmond AD (2017) Magnetic coordinate systems. Space Sci Rev 206(1-4):27-59

Lowes F (2000) An estimate of the errors of the IGRF/DGRF fields 1945-2000. Earth Planets Space 52(12):1207-1211

Macmillan S, Finlay CC (2011) The International Geomagnetic Reference Field. In: Mandea M, Korte M (eds) Geomagnetic Observations and Models, vol 5. Cham, Springer. pp 265-276

Macmillan S, Maus S (2005) International geomagnetic reference field-the tenth generation. Earth Planets Space 57(12):1135-1140. https://doi. org/10.1186/BF03351896

Macmillan S, Maus S, Bondar T, Chambodut A, Golovkov V, Holme R, Langlais B, Lesur V, Lowes F, Lühr H, Mai W, Mandea M, Olsen N, Rother M, Sabaka T, Thomson A, Wardinski I (2003) The 9th-Generation International Geomagnetic Reference Field. Geophys J Int 155(3):1051-1056. https://doi. org/10.1111/j.1365-246X.2003.02102.x, https://academic.oup.com/gji/ article-pdf/155/3/1051/6103811/155-3-1051.pdf

Mandea M, Macmillan S (2000) International geomagnetic reference field-the eighth generation. Earth Planets Space 52(12):1119-1124. https://doi. org/10.1186/BF03352342

Maus S, Macmillan S, Chernova T, Choi S, Dater D, Golovkov V, Lesur V, Lowes F, Lühr H, Mai W, McLean S, Olsen N, Rother M, Sabaka T, Thomson A, Zvereva T (2005) The 10th-Generation International Geomagnetic Reference Field. Geophys J Int 161(3):561-565. https://doi.org/10.1111/ j.1365-246X.2005.02641.x, https://academic.oup.com/gji/articlepdf/161/3/561/6065899/161-3-561.pdf

Merrill RT, McElhinny MW, McFadden PL (1996) The Magnetic Field of the Earth: Paleomagnetism, the core, and the deep mantle, International Geophysics Series, vol 63. Cambridge, Academic Press,

Metman MC, Beggan CD, Livermore PW, Mound JE (2020) Forecasting yearly geomagnetic variation through sequential estimation of core flow and magnetic diffusion. Earth Planets Space. https://doi.org/10.1186/s4062 3-020-01193-3

Minami T, Nakano S, Lesur V, Takahashi F, Matsushima M, Shimizu H, Nakashima R, Taniguchi H, Toh H (2020) A candidate secular variation model for 
IGRF-13 based on MHD dynamo simulation and 4DEnVar data assimilation. Earth Planets Space. https://doi.org/10.1186/s40623-020-01253-8 Olsen N, Holme R, Hulot G, Sabaka T, Neubert T, Tøffner-Clausen L, Primdah F, Jørgensen J, Léger JM, Barraclough D, Bloxham J, Cain J, Constable C, Golovkov V, Jackson A, Kotzé P, Langlais B, Macmillan S, Mandea M, Merayo J, Newitt L, Purucker M, Risbo T, Stampe M, Thomson A, Voorhies C (2000) Ørsted Initial Field Model. Geophys Res Lett 27(22):3607-3610. https://doi.org/10.1029/2000GL011930, https://agupubs.onlinelibrary. wiley.com/doi/abs/10.1029/2000GL011930, https://agupubs.onlinelibr ary.wiley.com/doi/pdf/10.1029/2000GL011930

Panovska S, Korte M, Constable CG (2019) One hundred thousand years of geomagnetic field evolution. Rev Geophys 57(4):1289-1337. https://doi. org/10.1029/2019RG000656

Pavón-Carrasco FJ, Marsal S, Torta JM, Catalán M, Martín-Hernández F, Tordesillas JM (2020) Bootstrapping Swarm and observatory data to generate candidates for the DGRF and IGRF-13. Earth Planets Space. https://doi. org/10.1186/s40623-020-01198-y

Peddie NW (1982) International Geomagnetic Reference Field: the Third Generation. J Geomagnetism Geoelectricity 34(6):309-326. https://doi. org/10.5636/jgg.34.309

Petrov VG, Bondar TN (2020) IZMIRAN sub-model for IGRF-13. Earth Planets Space. https://doi.org/10.1186/s40623-020-01312-0

Reigber C, Lühr H, Schwintzer P (2002) CHAMP mission status. Adv Space Res 30(2):129-134

Ropp G, Lesur V, Baerenzung J, Holschneider M (2020) Sequential modelling of the Earth's core magnetic field. Earth Planets Space. https://doi. org/10.1186/s40623-020-01230-1

Rother M, Korte M, Morschhauser A, Vervelidou F, Matzka J, Stolle C (2020) The Magnum core field model as a parent for IGRF-13, and the recent evolution of the South Atlantic Anomaly. Earth Planets Space. https://doi. org/10.1186/s40623-020-01277-0

Sabaka TJ, Tøffner-Clausen L, Olsen N, Finlay CC (2020) CM6: A Comprehensive Geomagnetic Field Model Derived From Both CHAMP and Swarm Satellite Observations. Earth Planets Space. https://doi.org/10.1186/s4062 3-020-01210-5

Sanchez S, Wicht J, Bärenzung J (2020) Predictions of the geomagnetic secular variation based on the ensemble sequential assimilation of geomagnetic field models by dynamo simulations. Earth Planets Space. https://doi. org/10.1186/s40623-020-01279-y

Shen X, Zhang X, Yuan S, Wang L, Cao J, Huang J, Zhu X, Piergiorgio P, Dai J (2018) The state-of-the-art of the China Seismo-Electromagnetic Satellite mission. Science China Technological Sciences 61 (5):634-642

Tangborn A, Kuang W, Sabaka TJ, Yi C (2020) Geomagnetic secular variation forecast using the NASA GEMS ensemble Kalman filter: A candidate model for IGRF 2020. Earth, Planets and Space. https://doi.org/10.1186/ s40623-020-01324-W

Terra-Nova F, Amit H, Choblet G (2019) Preferred locations of weak surface field in numerical dynamos with heterogeneous core-mantle boundary heat flux: consequences for the South Atlantic Anomaly. Geophysical Journal International 217(2):1179-1199

Thébault E, Finlay CC, Beggan CD, Alken P, Aubert J, Barrois O, Bertrand F, Bondar T, Boness A, Brocco L, Canet E, Chambodut A, Chulliat A, Coïsson P, Civet F, Du A, Fournier A, Fratter I, Gillet N, Hamilton B, Hamoudi M, Hulot G, Jager T, Korte M, Kuang W, Lalanne X, Langlais B, Léger JM, Lesur V, Lowes FJ, Macmillan S, Mandea M, Manoj C, Maus S, Olsen N, Petrov V, Ridley V, Rother M, Sabaka TJ, Saturnino D, Schachtschneider R, Sirol O, Tangborn A, Thomson A, Tøffner-Clausen L, Vigneron P, Wardinski I, Zvereva T (2015) International Geomagnetic Reference Field: the 12th generation. Earth, Planets, and Space 67:79. https://doi.org/10.1186/ s40623-015-0228-9

Vigneron P, Hulot G, Leger JM, Jager T (2019) Core field modelling using ASM-V vector data on board the Swarm satellites. In: 9th Swarm data quality workshop, Faculty of Civil Engineering, CTU, Prague, Czech Republic, 16-20 September 2019

Wardinski I, Saturnino D, Amit H, Chambodut A, Langlais B, Mandea M, Thébault E (2020) Geomagnetic core field models and secular variation forecasts for the 13th International Geomagnetic Reference Field (IGRF13). Earth Planets Space. https://doi.org/10.1186/s40623-020-01254-7

Winch DE, Ivers DJ, Turner JPR, Stening RJ (2005) Geomagnetism and Schmidt quasi-normalization. Geophysical Journal International 160(2):487-504. https://doi.org/10.1111/j.1365-246X.2004.02472.x, https://academic.oup. com/gji/article-pdf/160/2/487/5970028/160-2-487.pdf

Yang Y, Hulot G, Vigneron P, Shen X, Zeren Z, Zhou B, Magnes W, Olsen N, Tøffner-Clausen L, Huang J, Zhang X, Wang L, Cheng B, Pollinger A, Lammegger R, Lin J, Guo F, Yu J, Wang J, Wu Y, Zhao X (2020) The CSES Global Geomagnetic Field Model (CGGM): An IGRF type global geomagnetic field model based on data from the China Seismo-Electromagnetic Satellite. Earth, Planets and Space. https://doi.org/10.1186/s40623-020-01316-w Zmuda AJ (1971a) The International Geomagnetic Reference Field: Introduction. Bull Int Assoc Geomag Aeronomy 28:148-152

Zmuda AJ (1971b) World magnetic survey 1957-1969. IAGA Bulletin No 28

\section{Publisher's Note}

Springer Nature remains neutral with regard to jurisdictional claims in published maps and institutional affiliations.

\section{Submit your manuscript to a SpringerOpen ${ }^{\circ}$ journal and benefit from:}

- Convenient online submission

- Rigorous peer review

- Open access: articles freely available online

- High visibility within the field

- Retaining the copyright to your article

Submit your next manuscript at $\boldsymbol{\nabla}$ springeropen.com 